\title{
Dynamic Two-sided Matching Group Decision- making Model With Multi-form Preference Information for Configuring Tasks and Resources in Cloud Manufacturing
}

\section{Xuejiao Zhang}

Chongqing University College of Mechanical Engineering

Yu Yang ( $\nabla$ yuyang@cqu.edu.cn )

Chongqing University https://orcid.org/0000-0002-4049-0265

\section{Research Article}

Keywords: Dynamic two-sided matching, Group decision-making, Multi-form preference information Cloud manufacturing, Configuration tasks and resources

Posted Date: January 10th, 2022

DOI: https://doi.org/10.21203/rs.3.rs-1089719/v2

License: (c) (1) This work is licensed under a Creative Commons Attribution 4.0 International License.

Read Full License 


\title{
Dynamic two-sided matching group decision-making model with multi-form preference information for configuring tasks and resources in cloud manufacturing
}

\author{
Xuejiao Zhang ${ }^{1} \cdot$ Yu Yang ${ }^{1}$ \\ ${ }^{1}$ College of Mechanical Engineering, Chongqing University, Chongqing 400044, China \\ E-mails: xuejiao.zhang@cqu.edu.cn; yuyang@cqu.edu.cn; \\ Yu Yang; E-mail: yuyang@cqu.edu.cn
}

\begin{abstract}
Enterprises have been faced with the problem of how to optimize resource allocation in an uncertain environment by the expanding of manufacturing informatization. In the process of cloud manufacturing matching, group decision making organizations may provide uncertain preference information. However, preference information at various points have led to differing impacts of the final matching decision. it is necessary to study the dynamic two-sided matching. In this paper, the dynamic two-sided matching problem under the multi-form preference information was studied. Primarily, the problem of two-sided matching is described, then through group decision-making and uncertain preference information, an ordinal vector matrix is constructed. Afterwards, the comprehensive satisfaction matrix is calculated by using dynamic time-series weight and matching competition degree. Further, by introducing stable matching constraints, a multi-objective optimization model considering the satisfaction, fairness and stability of matching is constructed. Then the optimal matching result is obtained by solving the model. In addition, the presented method was verified through a case of cloud manufacturing. At the end, advantages of the presented model were demonstrated by comparison. Research results of this paper enrich the theoretical research of two-sided matching and provide an effective solution for cloud manufacturing matching in uncertain environments.
\end{abstract}

Keywords Dynamic two-sided matching . Group decision-making · Multi-form preference information Cloud manufacturing $\cdot$ Configuration tasks and resources

\section{Introduction}

Since the ITU first proposed the concept of Internet of Things in 2005, internet of Things technology is developing rapidly under the support of RFID, sensors, intelligent technology, etc. It has also rapidly changed the production, trading and operation mode of global enterprises, which will help to build a platform that can connect all kinds of manufacturing resources. (Zhao \& Wang 2016; Zhao \& Li 2017) In addition, with the development of high-performance computing technology, the traditional manufacturing industry is gradually forming a new mode of intelligent manufacturing, which provides the possibility for solving more complex manufacturing problems and carrying out large-scale collaborative manufacturing. Therefore, the concept of cloud manufacturing was first proposed in 2010. ( $\mathrm{Li}$ et al. 2010) As a cutting-edge manufacturing concept and manufacturing model, it integrates advanced technologies such as cloud computing, Internet of Things, and big data, and uses the network and cloud manufacturing service platform to organize online manufacturing resources according to user requirements, thereby providing users with various manufacturing services. In the context of the global manufacturing industries transform from production-oriented manufacturing to service-oriented manufacturing, due to the variability of the market and the diversity of user requirements, the traditional manufacturing system has experienced serious scheduling imbalance and waste of resources, which cannot adapt to the development trend of The Times. As a new mode of service-oriented manufacturing, cloud manufacturing can realize the collaboration between enterprises and the sharing of various social resources. At the same time, it also provided products and services with higher quality and lower cost. Therefore, cloud manufacturing plays an important role in the transformation and upgrading of the manufacturing industry. (Zhang 2020; Jia et al. 2020) 
With the development of cloud manufacturing technology, how to better match resources and tasks on the cloud manufacturing service platform to provide better services is a key issue in cloud manufacturing. There are multiple resource providers and demanders on the cloud manufacturing platform. The resource provider publishes the provided manufacturing resources to the cloud manufacturing platform and makes requirements for the partners. The demander puts forward requirements on the resource provider according to the manufacturing tasks that need to be completed. Then the system performs two-sided matching according to the conditions proposed by both agents. As aforementioned, Fig. 1 is provided to describes the cloud manufacturing platform in this paper. Therefore, to realize the interconnection and sharing of resources, two-sided matching must be solved. Zhao et al. (2016)put forward a cloud service two-sided matching model based on service quality. Firstly, the evaluation information of both sides is quantified into a calculable value through the cloud model. Then the variable fuzzy recognition method is used to calculate the comprehensive satisfaction of multi-index information. Finally, with the goal of maximizing the satisfaction of both sides' service quality, the problem of matching between the two parties in the cloud manufacturing platform is solved. Zhao and Li (2017) proposes a method based on prospect theory and multi-attribute evaluation. Under the premise of considering the number of matches, the "many-to-many" matching algorithm for stable matching schemes is solved. In order to search for resources that meet user needs from the resource pool of the cloud manufacturing platform accurately, and achieve higher efficiency matching while maintaining higher matching accuracy, Jia et al. (2020) proposes an efficient resource demand matching strategy. Firstly, the resources in the cloud service pool are clustered to determine the alternative resource cluster, and then the alternative resources in the alternative resource cluster are screened and matched from the state information, function information and service information of the resource respectively. Li et al. (2020) cloud manufacturing model was proposed and the development of two-sided matching the overall framework design task and knowledge resources. By constructing a two-sided matching satisfaction evaluation index system, processing multi-index satisfaction evaluation information, and solving a multi-objective two-sided matching decision-making model, the efficiency of product design task has been improved. With the increasing complexity of the actual matching decision problems, in the process of two-sided matching, there are often situations such as the lack of matching preference information, the hesitation and fuzziness of matching preference information, which makes it difficult to express quantitatively or express in multiple forms. This is due to the uncertainty and complexity of the matching environment as well as cognitive limitations and differences, so some traditional matching methods are no longer applicable or need to be supplemented and improved to some extent.

The other parts of this paper are described separately. First, describe the research literature. Secondly, the definition of two-sided matching, dynamic matching time-series weight and various forms of preference information are given, which introduce the satisfaction, fairness and stability of matching. The process of establishing and solving the model is further explained. In addition, an example of matching cloud manufacturing tasks and cloud manufacturing resources is presented. Then, implement the discussion. Finally, the conclusion is given and the future work is prospected.

\section{Literature review}

Two-sided matching decision theory originated in the 1960s. Gale et al. (1962) studied the problems of male and female marriages and the enrollment of students, then proposed the Gale-Shapley algorithm to ensure stable matching. The concept of two-sided matching was explicitly proposed by Professor Roth of Harvard University in 1985, and he also made an in-depth study on the matching between the intern hospital and the intern students. (Roth 1985) Since then, two-sided matching theory has been widely used in venture capital matching, trading matching and other research, such as Chandrashekhar et al. (2011) has developed a procedure that can conduct automated negotiation when two-sided information is uncertain, and this procedure can quickly get effective and fair deals. Kushnir (2013) proposed a game matching model with incomplete information between workers and enterprises, and pointed out that although useless information is helpful to convey information about the preferences of participants, it will lead to information asymmetry, thus producing unsuccessful matches. Chen et al. (2014) constructed a dynamic model to solve bilateral matching under the condition of uncertain preference. Aiming at the two-sided matching problem with uncertain preference order, a dynamic model to solve the two-sided matching problem with uncertain 
preference order is constructed by introducing the degree of ordered deviation. Chakraborty et al. (2015) has studied the problem of many-to-one matching with incomplete information and proposed a mechanism model to achieve group stability matching. Therefore, the in-depth study of matching problem has theoretical significance and practical value. At present, the research of two-sided matching decision method considering complete and incomplete preference information is the focus of scholars. $\mathrm{Xu}$ (2004) developed a multi-attribute group decision making method based on uncertain language information of ULOWA and ULHA operators, and applied this method to the evaluation of tenure and promotion of university teachers. You et al. (2013) converted the uncertain preference order information into the scheme voting number information to establish the group voting matrix, based on which the optimization model of scheme ordering was determined, so as to solve the multi-index group decision making problem with uncertain preference order. When experts provide preference information in the form of an uncertain preference order, Fan et al. (2010) by constructing a decision matrix in the form of probabilities and a collective probability matrix on alternatives with regard to ranking positions to establish an optimization model, and the ranking of alternatives can be obtained by solving the model. By synthesizing borda score matrix and difference degree matrix, Yue (2015) constructed the matching degree matrix for the subjects of both sides and gave a bilateral matching decision method based on order relation information, then by synthesizing borda score matrix and difference degree matrix, constructed the matching degree matrix for the subjects of both sides and gave a bilateral matching decision method based on order relation information. Yue et al. (2015) studies the two-sided matching problem in which the preference information of matching subjects is expressed in terms of multi-granularity uncertain language. Sun et al. (2017) addresses the problem of two-sided matching with preference information in the form of uncertain preference order, uncertain linguistic variables and incomplete complementary judgment matrix. based on risk function, probability and nonlinear programming theory, combined with the characteristics of uncertain preference order, uncertain linguistic variables and incomplete complementarity, the judgment matrix construct the order value calculation rules and propose a two-sided matching decision-making method. Zhao et al. (2018) converts the preference information given by the two-sided subjects into satisfaction with the generalized superior order method, and gives the time sequence weight based on the exponential decay model, and then integrates the satisfaction into the comprehensive satisfaction, so as to solve the dynamic two-sided matching problem of the preference information given by the matching subjects. Fan et al. (2018) believes that the satisfaction of matching subjects to potential matching results is closely related to psychological behavior, so he proposes a decision-making method that considers the psychological behavior of two-sided matching subjects. On the basis of prospect theory, Zhang et al. (2018) proposed a decision-making method considering the different risk attitudes of bilateral subjects in dealing with loss and gain for two-sided matching problem with preference information in both evaluation score and language phrase form and with expectation of two different types of subjects. According to the expected value, accumulated prospect theory and normalized formula, Yue (2013) constructed the profit and loss matrix and normalized prospect matrix of two-sided matching subjects respectively. On this basis, the multi-objective two-sided matching optimization model is constructed, and the two-sided matching problem with uncertain preference order information considering the expected value of the subject is solved. For the two-sided matching problem with incomplete score information, Yue (2013) converts incomplete score information into incomplete satisfaction information to obtain the maximum value of the total satisfaction of both parties, so as to build a multi-objective matching model. Yue (2014) points out that in some cases matching subjects may be more concerned with improving their own satisfaction than with stable matching. Therefore, this paper introduces the formula of satisfaction degree calculation. At the same time, existing researches pay less attention to the two-sided matching problem in which subject preference is in the form of score information. This paper proposes a decision analysis method to solve the two-sided matching problem with score information. Yue et al. (2015) introduced the concept of perfect two-sided matching and discussed its existence, and further presented the decision method of perfect two-sided matching in the case of existence and non-existence. On this basis, he proposed an algorithm to solve the problem of two-sided matching based on incomplete ordered value information.

Among them, the discussion of two-sided matching based on preference information has always been the focus of scholars. ( $\mathrm{Li}$ et al. 2020) As the uncertainty faced by decision-makers in decision-making becomes more and more significant, the traditional precise numbers can no longer accurately express the preferences 
of decision-makers. Therefore, in the two-sided matching problem, decision-makers will give different forms of preference information for different evaluation attributes, such as uncertain preference ordinal, uncertain linguistic variables, etc. When decision-makers are not sure, not interested or not willing to express their opinions about some judgments, some elements in the complementary judgment matrix will be missing. However, there are few studies on two-sided matching decisions that consider multiple forms of preference information at the same time. In addition, from the existing research results, the research of two-sided matching decision problem is almost limited to the static matching problem. In the real matching problem, the decision information will change over time, so it is necessary to consider the preference information at various points to carry out the dynamic matching research. (Zhao et al. 2018) At the same time, due to the differences in expert knowledge system, judgment level and individual preference, decision-makers should select several experts for Group decision-making. In addition, the satisfaction, fairness and stability of matching are closely related to the satisfaction of matching subjects to the matching results, which is an important basis for evaluating the merits of two-sided matching scheme. In the existing two-sided matching models, most of them are based on the satisfaction perspective of matching. If the fairness and stability of matching are ignored, the original matching scheme may fail.

In view of this, this paper is aimed at one-to-one dynamic two-sided matching problems that under the preference information of uncertain linguistic variable, uncertain preference ordinal and incomplete complementary matrix which proposed by experts, a matching optimization model considering the satisfaction, fairness and stability of two-sided matching subjects is proposed. Through the solution of this model, the two-sided matching between cloud manufacturing tasks and cloud manufacturing resources is realized.

\section{Preliminaries}

\section{1 Description of the two-sided matching problem}

The basic description about a two-sided matching is set out. The following notations are used to represent this problem. Let $\mathrm{X}$ and $\mathrm{Y}$ be two-sided matching subjects. (Li et al.2020) Both $\mathrm{X}$ and $\mathrm{Y}$ are one of the subjects. $X=\left\{X_{1}, X_{2}, \cdots X_{m}\right\}$ represents the set of subjects on the side $X$, where $X_{i}$ denotes the $i$ th subject of the side $X, i \in M=\{1,2, \cdots m\} ; Y=\left\{Y_{1}, Y_{2}, \cdots Y_{n}\right\}$ represents the set of subjects on the side $Y$, where $Y_{j}$ denotes the $j$ th subject of the side $\mathrm{Y}, \mathrm{j} \in \mathrm{N}=\{1,2, \cdots \mathrm{n}\}$; where $\mathrm{m}, \mathrm{n} \geq 2$. For the convenience of analysis, the two-sided matching problem with side $\mathrm{X}$, side $\mathrm{Y}$ and the intermediary is shown in Fig2.

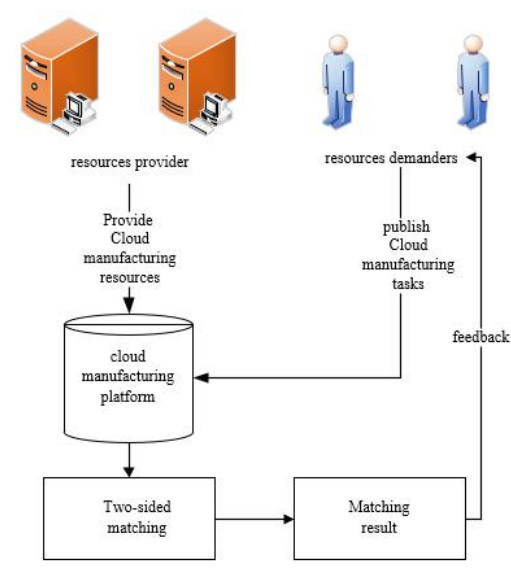

Fig. 1 The matching model of cloud manufacturing platform

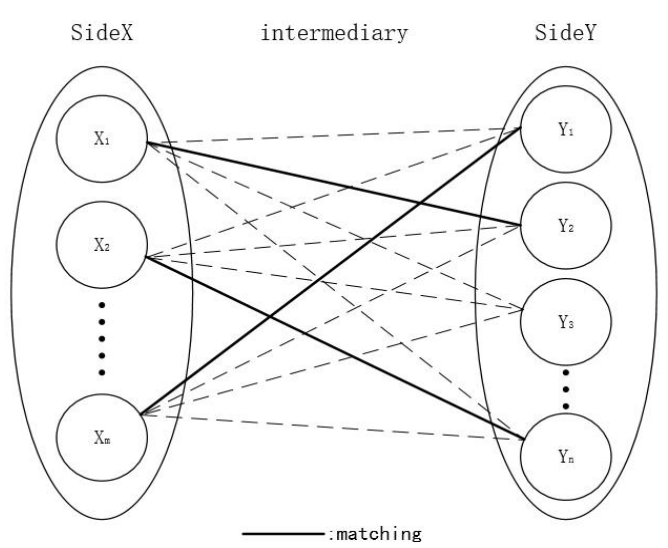

Fig. 2 Two-sided matching problem

In Fig2, $X_{i}$ is connected with $Y_{j}$ by dashed lines, which denotes that $X_{i}$ is potential matching with $Y_{j}$. If $X_{i}$ is connected with $Y_{j}$ by a solid line, which denotes that $X_{i}$ is really matched with $Y_{j}$.

Definition $1 \mu: X \cup Y \rightarrow X \cup Y$ is a one-to-one two-sided matching, if and only if $\forall X_{i} \in X, \forall Y_{j} \in Y$ satisfies the 
following conditions (Fan et al.2018; Jiang et al. 2017; Jiang et al. 2016)

(i) $\mathrm{u}\left(\mathrm{X}_{\mathrm{i}}\right) \in \mathrm{Y} \cup\left\{\mathrm{X}_{\mathrm{i}}\right\}$

(ii) $\mathrm{u}\left(\mathrm{Y}_{\mathrm{j}}\right) \in \mathrm{X} \cup\left\{\mathrm{Y}_{\mathrm{i}}\right\}$;

(iii) if $\mathrm{u}\left(\mathrm{X}_{\mathrm{i}}\right)=\mathrm{Y}_{\mathrm{j}}$, then $\mathrm{u}\left(\mathrm{Y}_{\mathrm{j}}\right)=\mathrm{X}_{\mathrm{i}}$;

(iv) if $\mathrm{u}\left(\mathrm{Y}_{\mathrm{j}}\right)=\mathrm{X}_{\mathrm{i}}$, then $\mathrm{u}\left(\mathrm{X}_{\mathrm{i}}\right) \in \mathrm{Y}_{\mathrm{j}}$;

(v) If $\forall j, j^{\prime} \in J, j \neq j^{\prime}, u\left(X_{i}\right)=Y_{j}$, then $u\left(X_{i}\right) \neq Y_{j}$;

(vi) If $\forall i, i^{\prime} \in I, i \neq i^{\prime}, u\left(Y_{j}\right)=X_{i}$, then $u\left(Y_{j}\right) \neq X_{i}$;

Specially, if $X_{i}$ is unmatched in $u$, then $u\left(X_{i}\right)=X_{i}$; if $Y_{j}$ is unmatched in $u$, then $u\left(Y_{j}\right)=Y_{j}$.

\section{2 Concept of multi-form preference information}

Definition 2 Let $\tilde{R}_{i}$ be the preference information of the side $\mathrm{Y}$ given by the $\mathrm{X}_{\mathrm{i}}$ of side $\mathrm{X}, \tilde{T}_{j}$ be the preference information of the side $\mathrm{X}$ given by the $\mathrm{Y}_{\mathrm{i}}$ of side $\mathrm{Y}$, where $\tilde{R}_{i}$ and $\tilde{T}_{j}$ are a form of uncertain preference ordinal, uncertain preference ordinal and Incomplete complementary judgment matrix.

Definition 3 Let $\mathrm{Z}^{+}$be the set of positive integers. $\tilde{R}=\left[\tilde{r}_{i j}\right]_{\mathrm{m} \times \mathrm{n}}$, an uncertain preference ordinal $\tilde{r}_{i j}$ is denoted by $\tilde{r}_{i j}=\left\{r_{i j}^{L}, r_{i j}^{L}+1, \cdots r_{i j}^{U}\right\}$, where $r_{i j}^{L}, r_{i j}^{L}+1, \cdots r_{i j}^{U} \in \mathrm{Z}^{+}, r_{i j}^{L} \leq r_{i j}^{U}, r_{i j}^{L}$ and $r_{i j}^{U}$ are the lower bound and upper bound of $\tilde{r}_{i j}$. For simplicity, we express $\tilde{r}_{i j}$ as $\tilde{r}_{i j}=\left[r_{i j}^{L}, r_{i j}^{U}\right]$. Especially, if $r_{i j}^{L}=r_{i j}^{U}$, then $\tilde{r}_{i j}$ reduced to a ranking ordinal. $\widetilde{T}=\left[\tilde{t}_{i j}\right]_{\mathrm{m} \times \mathrm{n}}$, an uncertain preference ordinal $\tilde{r}_{i j}$ is denoted by $\tilde{t}_{i j}=\left\{t_{i j}^{L}, t_{i j+1}^{L}, \cdots t_{i j}^{U}\right\}$, where $t_{i j}^{L}$, $\underset{t_{i j}+1}{L}, \cdots t_{i j}^{U} \in \mathrm{Z}^{+}, \quad \stackrel{L}{t_{i j}} \leq t_{i j}^{U}, \quad \stackrel{t}{t_{i j}}$ and $t_{i j}^{U}$ are the lower bound and upper bound of $\tilde{t}_{i j}$. For simplicity, we express $\tilde{t}_{i j}$ as $\tilde{t}_{i j}=\left[t_{i j}^{L}, t_{i j}^{U}\right]$. Especially, if $t_{i j}^{L}=t_{i j}^{U}$, then $\tilde{t}_{i j}$ reduced to a ranking ordinal. (Zhang and Zhu 2019; Fan et al. 2010; Fan et al. 2018)

Definition4 If $\tilde{r}_{i j}=\left[\mathrm{r}_{\mathrm{ij}}^{\mathrm{L}}, \mathrm{r}_{\mathrm{ij}}^{\mathrm{U}}\right]$ is an uncertain preference ordinal provided by the expert on an alternative, let $\tilde{p}_{i j}=\left[\tilde{P}_{i j}^{1}, \tilde{P}_{i j}^{2}, \cdots \tilde{P}_{i j}^{n}\right]$, denote the probability vector on $\tilde{r}_{i j}$, the element $\tilde{p}_{i j}^{k}$ denotes the probability when the alternative is ranked in the kth position, it is given by

$$
p_{i j}^{k}=\left\{\begin{array}{cl}
0, & \mathrm{k}=1 \cdots \mathrm{r}_{i j}^{L}-1, \\
1 /\left(r_{i j}^{U}-r_{i j}^{L}+1\right), & \mathrm{k}=\mathrm{r}_{i j}^{L} \cdots \mathrm{r}_{i j}^{U}, \\
0, & \mathrm{k}=\mathrm{r}_{i j}^{U}+1 \cdots \mathrm{n} .
\end{array}\right.
$$

Let $u_{\tilde{r}}=r_{i j}^{U}-\mathrm{r}_{i j}^{L}+1, u_{\tilde{r}}$ is regarded as the uncertainty degree of $\tilde{r}_{i j}$. Thus, the greater $u_{\tilde{r}}$ is, the greater the uncertainty degree of $\tilde{r}_{i j}$ will be. If $r_{i j}^{L}=r_{i j}^{U}, \quad \tilde{r}_{i j}$ reduced to a ranking ordinal, the elements of probability vector is given by (Fan et al.2018; Fan et al. 2010) 


$$
\tilde{p}_{i j}^{k}=\left\{\begin{array}{l}
0, \quad \mathrm{k}=1, \ldots \mathrm{r}_{i j}^{L}-1, \\
1, \quad \mathrm{k}=\mathrm{r}_{i j}^{L}=\mathrm{r}_{i j}^{U}, \\
0, \quad \mathrm{k}=\mathrm{r}_{i j}^{U}+1, \ldots \mathrm{n} .
\end{array}\right.
$$

Definition5 Suppose that $S=\left\{S_{i} \mid i=0,1, \cdots \tau\right\}$ is a finite and totally ordered discrete term set, where $S$ represents a possible value for a linguistic variable. To avoid loss of decision information and facilitate calculation, we extend the discrete term set $\mathrm{S}$ to a continuous term set $\bar{S}=\left\{\mathrm{S}_{a} \mid \mathrm{S}_{0} \leq \mathrm{S}_{u} \leq \mathrm{S}_{\tau}, \alpha \in[0, \tau]\right\}$, whose elements is required that there exist following (Xu 2004; Wei et al. 2007)

(i) If $i \geq j$, then $S \geq S_{j}$;

(ii) $\operatorname{Neg}\left(\mathrm{S}_{\mathrm{i}}\right)=\mathrm{S}_{\mathrm{j}}$ such that $\mathrm{j}=\tau-\mathrm{i}$;

(iii) $\operatorname{Max}\left(\mathrm{S}_{\mathrm{i}}, \mathrm{S}_{\mathrm{j}}\right)=\mathrm{S}_{\mathrm{i}}$, if $\mathrm{S}_{\mathrm{Z}} \geq \mathrm{S}_{\mathrm{j}}$;

(iv) $\operatorname{Min}\left(\mathrm{S}_{\mathrm{i}}, \mathrm{S}_{\mathrm{j}}\right)=\mathrm{S}_{\mathrm{i}}$, if $\mathrm{S}_{\mathrm{i}} \leq \mathrm{S}_{\mathrm{j}}$;

Let $\tilde{S}=\left[\mathrm{S}_{a}, \mathrm{~S}_{\beta}\right]$, where $\mathrm{S}_{a}, \mathrm{~S}_{\beta} \in \bar{S}, \mathrm{~S}_{\alpha}$ and $\mathrm{S}_{\beta}$ are the lower and the upper limits, respectively, we call $\tilde{S}$ the uncertain linguistic variable.

Definition6 $\tilde{s}_{1}=\left[s_{\alpha 1}, s_{\beta 1}\right]$ is a uncertain linguistic variable. Let len $\left(\tilde{s}_{1}\right)=\beta_{1}-\alpha_{1}$ denotes the length of uncertain linguistic variable. (Wei et al. 2007) Similarly, let $\tilde{s}_{2}=\left[s_{\alpha 2}, s_{\beta 2}\right]$, len $\left(\widetilde{s}_{2}\right)=\beta_{2}-\alpha_{2}$. Then the possible degree of $\widetilde{s}_{1} \geq \widetilde{s}_{2}$ is defined as follows:

$$
p\left(\tilde{s}_{1} \geq \tilde{s}_{2}\right)=\frac{\max \left(0, \operatorname{len}\left(\tilde{\mathbf{s}}_{1}\right)+\operatorname{len}\left(\tilde{s}_{2}\right)-\max \left(\beta_{2}-\alpha_{1}, 0\right)\right)}{\operatorname{len}\left(\tilde{\mathbf{s}}_{1}\right)+\operatorname{len}\left(\tilde{\mathbf{s}}_{2}\right)}
$$

Definition7 For convenience, let the judgment matrix $C^{l}=\left(C_{i j}^{l}\right)_{\mathrm{n} \times \mathrm{n}}$, if there are both complete and incomplete elements in the judgment matrix, and the non-incomplete elements satisfy $C_{i j}^{l}+C_{j i}^{l}=1, C_{i i}^{l}=0.5$, $C_{i j}^{l} \geq 0$, the judgment matrix is called an incomplete complementary judgment matrix. (Liu et al. 2013) In the incomplete complementary judgment matrix $C^{l}=\left(C_{i j}^{l}\right)_{\mathrm{n} \times \mathrm{n}}$, the incomplete element $C_{i j}^{l}$ is represented by the unknown number x, obviously, the incomplete element $C_{j i}^{l}$ is represented by 1-x. Similarly, suppose that the sorting vector of $C^{l}$ is shown in $W^{l}=\left(w_{1}^{l}, w_{2}^{l}, \ldots, w_{n}^{l}\right), w_{j}^{l}>0, j=1,2, \ldots, n, \sum_{j=1}^{n} w_{j}=1$.

\section{3 Determination method of time-series weight in dynamic two-sided matching}

In the actual two-sided matching problem, the influence of information at different moments on the matching decision should be measured by the method of assigning weights. The amount of information that the matching agent has will continue to increase with time. Conversely, the farther away from the moment of final matching decision-making, the less information the matching agent has, and the impact of the matching decision-making will be smaller. Through analysis, it is concluded that the weight at different times has the characteristic of exponential decay in the process of change, so in this paper, we use the exponential decay model to determine the weight.

Definition8 $T=\left\{t_{1}, t_{2} \cdots t_{p}\right\}$ which is a discrete time series, represents the time series inspected by the two-sided 
matching subjects. $t_{k}$ denotes the $k$ th moment of this time series. The weight of $k$ th moment is $\mathrm{w}_{k}$. Suppose that $\mathrm{C}_{0}$ is a constant and $\lambda$ is a attenuation coefficient, then

$$
w_{k}=C_{0} e^{\lambda\left(t_{k}-t_{p}\right)}, \mathrm{k}=1,2 \cdots \mathrm{p}
$$

Where $\mathrm{C}_{0} \geq 0$ is a constant. $0 \leq \lambda \leq 1$ is the attenuation coefficient.

Because the weights satisfy formula

$$
\begin{gathered}
\sum_{k=1}^{p} w\left(t_{k}\right)=\sum_{k=1}^{p} C_{0} e^{\lambda\left(t_{k}-t_{p}\right)}=1 \\
\text { so } C_{0}=\frac{1}{\sum_{k=1}^{p} e^{\lambda\left(t_{k}-t_{p}\right)}} \\
w\left(t_{k}\right)=\frac{e^{\lambda t_{k}}}{\sum_{k=1}^{p} e^{\lambda t_{k}}}, \mathrm{k}=1,2 \cdots \mathrm{p}
\end{gathered}
$$

Especially, when $\mathrm{T}=\{1,2 \cdots \mathrm{p}\}$ which is a continuous time. The formula can be transformed into

$$
w\left(t_{k}\right)=\frac{e^{\lambda k}\left(1-e^{\lambda}\right)}{e^{\lambda}\left(1-e^{\lambda p}\right)}, \mathrm{k}=1,2 \cdots \mathrm{p}
$$

Attenuation coefficient reflects the cumulative rate of information that the matching agent has with the time goes by, so the matching agents can determine the value of $\lambda$ according to the actual situation. (Zhao et al. 2018; Mao et al. 2014)

\section{4 The satisfaction, fairness and stability of two-sided matching}

The satisfaction, fairness and stability of matching play an important role in measuring the pros and cons of two-sided matching schemes. The satisfaction of matching can maximize the two-sided matching subjects, the fairness of matching can reduce the conflict of interest of two-sided matching subjects, and the stability of matching can maintain a stable matching relationship between two-sided matching subjects.

Let $\mathrm{D}=\left\{\mathrm{d}_{1}, \mathrm{~d} 2 \cdots d_{\xi}\right\}$ be a set of two-sided matching schemes, where $\xi \geq 2, \mathrm{x}_{\mathrm{ij}}$ is a $0-1$ variable, when $\mathrm{x}_{\mathrm{ij}}=0$, it means $\mathrm{x}_{\mathrm{i}}$ and $\mathrm{y}_{\mathrm{j}}$ do not match, when $\mathrm{x}_{\mathrm{ij}}=1$, it means $\mathrm{x}_{\mathrm{i}}$ and $\mathrm{y}_{\mathrm{j}}$ matches.

Definition9 The satisfaction of matching refers to the matching scheme that maximizes the sum of satisfaction of two-sided matching subjects in the collection of two-sided matching schemes, expressed as:

$\mathrm{f}(\mathrm{u})=\max \left\{\sum_{i=1}^{m} \sum_{j=1}^{n}\left(\alpha_{i j}+\beta_{i j}\right) x_{i j}\right\}$

Definition10 The fairness of matching refers to the matching scheme that minimizes the sum of the deviations of two-sided matching subjects' satisfaction in the set of two-sided matching schemes, which is expressed as: $\mathrm{g}(\mathrm{u})=\min \left\{\sum_{i=1}^{m} \sum_{j=1}^{n}\left|\alpha_{i j}-\beta_{i j}\right| x_{i j}\right\}$.

Definition11 The stability of matching refers to: for any pair of matching subjects in the matching scheme, 
except for the current matching subjects $X_{i}$ and $Y_{j}$, no other matching subjects can make each subject obtain higher satisfaction than the existing matching subjects. It is expressed as: there is no hindering stable pair in two-sided matching $\mathrm{u}$, then $\mathrm{u}$ is called stable matching.

The hindering stable pair is defined as: there is $m_{l} \in M, n_{k} \in N$ that satisfies

$u\left(m_{i}\right)=n_{k}, u\left(m_{l}\right)=n_{j}$ and $r_{i j} \leq r_{i k}, t_{i j} \leq t_{l j}$; or there is $n_{k} \in N$ that satisfies $u\left(m_{i}\right)=n_{k}, u\left(n_{j}\right)=n_{j}$ and $r_{i j} \leq r_{i k}$.

\section{Construction and solution of the two-sided matching model}

\subsection{Matching preference information translates into matching satisfaction}

Let $R_{i}=\left(r_{i 1}, r_{i 2} \cdots r_{i n}\right)$, be the ordinal value vector of the side $Y$ given by the $X i$ of side $X, T_{j}=\left(t_{1 j}, t_{2 j} \cdots t_{m i}\right)$ be the preference information of the side $\mathrm{X}$ given by the $\mathrm{Y}_{\mathrm{i}}$ of side $\mathrm{Y}$. And then, the ordinal value matrix of the side $X$ given by $Y$ can be constructed from $R_{i}$, which is denoted by $R=\left[R_{1}, R_{2} \cdots R_{m}\right]$. Similarly, $T=\left[T_{1}, T_{2} \cdots T_{n}\right]$ is the ordinal value matrix of the side $Y$ given by $X$. (Sun et al. 2017; Li et al. 2012) Suppose $Y=\left\{y_{1}, y_{2} \cdots\right.$ $\left.\mathrm{y}_{\mathrm{n}}\right\}(\mathrm{n} \geq 2)$ is the group of finite alternatives, $\mathrm{y}_{\mathrm{j}}$ denotes the $j$ th alternative, $\mathrm{E}=\left\{\mathrm{e}_{1}, \mathrm{e}_{2} \cdots \mathrm{e}_{\mathrm{m}}\right\}(\mathrm{m} \geq 2)$ is a set of experts, $\mathrm{e}_{\mathrm{i}}$ denotes the $i$ th expert. $\mathrm{W}=\left\{\mathrm{W}_{1}, \mathrm{~W}_{2} \cdots \mathrm{W}_{\mathrm{m}}\right\}$ is the weight vector of the experts, which denotes the importance degree of experts, such that $\sum_{i=1}^{m} w_{i}=1$ and $0 \leq \mathrm{w}_{\mathrm{i}} \leq 1, \mathrm{i}=1,2 \cdots \mathrm{n}$.

(I) The preference information given by experts is the uncertain preference ordinal

$$
\tilde{r}_{i j}=\left[r_{i j}^{L}, r_{i j}^{U}\right], \quad r_{i j}^{L}, \quad r_{i j}^{U} \in \mathrm{Z}^{+}, \mathrm{i}=1,2 \ldots \mathrm{m}, \mathrm{j}=1,2 \cdots \mathrm{n} . \quad \tilde{r}_{i j} \text { denotes the preference on alternative } \mathrm{Y}_{\mathrm{j}} \text { provided }
$$

by expert $\mathrm{e}_{\mathrm{i}} . \tilde{p}_{i j}=\left(p_{i 1}, p_{i 2} \cdots p_{i n}\right)$ is a probability vector on uncertain preference ordinals $\tilde{r}_{i j}$. For the convenience of analysis, the probability vector matrix based on $\tilde{p}_{i j}$ is constructed as follows:

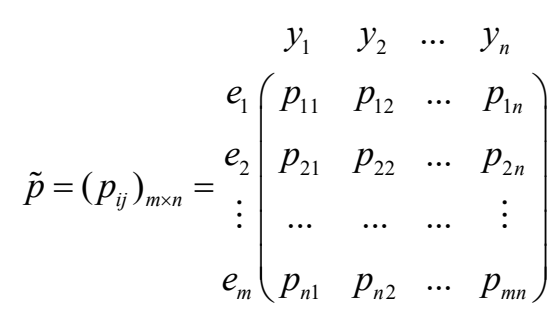

The elements of the $j$ th column of decision matrix $\tilde{p}_{i j}$ and $\mathrm{W}_{\mathrm{i}}$ are aggregated to form the collective probability vector on alternative $q_{j k}$.

$$
\begin{aligned}
& q_{j k}=\sum_{i=1}^{m} w_{i} p_{i j}, \quad \mathrm{j}=1,2 \cdots \mathrm{n} \\
& \sum_{k=1}^{n} q_{j k}=1 \quad \mathrm{k}=1,2 \cdots \mathrm{n}
\end{aligned}
$$


Based on $q_{j k}$, the following collective probability matrix $\tilde{Q}=\left(q_{j k}\right)_{\mathrm{n} \times \mathrm{n}}$ can be constructed as follows:

$$
\tilde{Q}=\stackrel{y_{1}}{y_{2}} \underset{\vdots}{y_{n}}\left(\begin{array}{ccccc}
1 & 2 & \ldots & n \\
q_{11} & q_{12} & \ldots & q_{1 n} \\
q_{21} & q_{22} & \ldots & q_{2 n} \\
\ldots & \ldots & \ldots & \vdots \\
q_{n 1} & q_{n 2} & \ldots & q_{n n}
\end{array}\right)
$$

In order to determine the ranking position of each alternative, let $x_{j k}$ be a $0-1$ variable, and $\sum_{k=1}^{n} x_{j k}=1, \mathrm{j}=1 \cdots \mathrm{n}$, $\sum_{j=1}^{n} x_{j k}=1, \mathrm{k}=1 \cdots \mathrm{n} . x_{j k}=1$ denotes that the alternative $\mathrm{y}_{\mathrm{j}}$ is ranked in the kth position, if not, $x_{j k}=0$. Similarly, let $g_{j k}=\max \left\{\operatorname{In} q_{t s} \mid t, s=1 \cdots n\right\}-\operatorname{In} q_{j k}, \mathrm{j}, \mathrm{k}=1 \cdots \mathrm{n}$. After that, the minimum of the formula $\sum_{j=1}^{n} \sum_{k=1}^{n} g_{j k} x_{j k}$ that based on the collective probability matrix Q is calculated by using Hungarian method. (Fan et al. 2018;Kuhn 1955) Then $\mathrm{x}_{\mathrm{jk}} *$ is the feasible solution.

Using the method of (I), the ordinal value vector $\mathrm{R}_{i}=\left(\mathrm{r}_{i}, \mathrm{r}_{\mathrm{i}}, \cdots \mathrm{r}_{i n}\right)$ that the side $\mathrm{Y}$ given by the side $\mathrm{X}$ is obtained. Similarly, when the preference information given by cloud manufacturing resources about cloud manufacturing tasks is the uncertain preference order, method (I) can be used to obtain the order vector $\mathrm{T}_{j}=$ $\left(\mathrm{t}_{i j}, \mathrm{t}_{2 j} \cdots \mathrm{t}_{m j}\right)$ of cloud manufacturing resources to cloud manufacturing tasks.

(II) The preference information given by experts is the uncertain linguistic variable

$a_{i j} \in \bar{s}, \mathrm{i}=1,2 \cdots \mathrm{m}, \mathrm{j}=1,2 \cdots \mathrm{n} . a_{i j}$ denotes the preference on alternative $\mathrm{Y}_{\mathrm{j}}$ provided by expert $\mathrm{e}_{\mathrm{i}}$.

$\tilde{A}=\left(a_{i 1}, a_{i 2} \cdots a_{i n}\right)$ is a evaluation vector based on uncertain linguistic variable. For the convenience of analysis, $\tilde{A}$ is constructed as follows:

$$
\begin{aligned}
& \begin{array}{llll}
y_{1} & y_{2} & \ldots & y_{n}
\end{array} \\
& \tilde{A}=\begin{array}{c}
e_{1} \\
e_{2} \\
\vdots \\
e_{m}
\end{array}\left(\begin{array}{ccccc}
a_{11} & a_{12} & \ldots & a_{1 n} \\
a_{21} & a_{22} & \ldots & a_{2 n} \\
\ldots & \ldots & \ldots & \vdots \\
a_{m 1} & a_{m 2} & \ldots & a_{m n}
\end{array}\right)
\end{aligned}
$$

Then let $\tilde{R}=\left(r_{i j}\right)_{m \times n}$ be the weighted group comprehensive decision matrix.

$$
r_{i j}=w_{i} a_{i j}, i \in m, j \in n \text {. }
$$

After that, let $\tilde{r}^{+}=\left(r_{1}^{+}, r_{2}^{+} \cdots r_{n}^{+}\right)$be the positive ideal solution of the weighted group comprehensive decision matrix $\tilde{R}=\left(r_{i j}\right)_{m \times n}, r_{j}^{+}=\left[r_{j}^{L}, r_{j}^{U}\right]=\left[\max _{i} r_{i j}^{L}, \max _{i} r_{i j}^{U}\right]$. The possibility degree between weighted group comprehensive decision value of the $i$ th solution that is shown in $\tilde{r}_{i}=\left(r_{i 1}, r_{i 2} \cdots r_{i n}\right)$ and the positive ideal solution that is shown in $\tilde{r}^{+}=\left(r_{1}^{+}, r_{2}{ }^{+} \ldots r_{n}{ }^{+}\right)$can be obtained by applying the 


$$
\begin{aligned}
& \left(p\left(\tilde{s}_{1} \geq \tilde{s}_{2}\right)=\frac{\max \left(0, \operatorname{len}\left(\tilde{\mathrm{s}}_{1}\right)+\operatorname{len}\left(\tilde{s}_{2}\right)-\max \left(\beta_{2}-\alpha_{1}, 0\right)\right)}{\operatorname{len}\left(\tilde{\mathrm{s}}_{1}\right)+\operatorname{len}\left(\tilde{\mathbf{s}}_{2}\right)}\right) \\
& p\left\{\tilde{r}_{i} \geq \tilde{r}^{+}\right\}=\frac{1}{n} \sum_{j=1}^{n} p\left(\tilde{r}_{i j} \geq \tilde{r}_{j}^{+}\right), i \in n
\end{aligned}
$$

The ordering of alternatives can be determined by the value of $p\left\{\tilde{r}_{i} \geq \tilde{r}^{+}\right\}$The higher the value, the higher the ranking of the alternative.

Using the method of (II), the ordinal value vector $R_{i}=\left(r_{i 1}, r_{i 2} \cdots r_{i n}\right)$ that the side $Y$ given by the side $X$ is obtained. Similarly, when the preference information given by cloud manufacturing resources about cloud manufacturing tasks is the uncertain linguistic variable, method (II) can be used to obtain the order vector $\mathrm{T}_{\mathrm{j}}=\left(\mathrm{t}_{\mathrm{i}}, \mathrm{t}_{2 \mathrm{j}} \cdots \mathrm{t}_{\mathrm{mij}}\right)$ of cloud manufacturing resources to cloud manufacturing tasks.

(III) The preference information given by experts is the incomplete complementary judgment matrix

When $C^{l}$ is the incomplete complementary judgment matrix, The incomplete complementary judgment matrix provided by expert $\mathrm{e}_{\mathrm{l}}, \mathrm{l}=1,2 \cdots \mathrm{m}$ for subject $\mathrm{Y}$ is $C^{l}$, and the sorting vector of $C^{l}$ is $W^{l}=\left(w_{1}^{l}, w_{2}^{l}, \ldots, w_{n}^{l}\right)$. W $W^{l}$ can be transformed into $W^{l}=\left(1 / \sum_{i=1}^{n} \frac{c_{11}^{l}}{c_{1 i}^{l}} \int^{1} \sum_{i=1}^{n} \frac{c_{i 2}^{l}}{c_{2 i}^{l}} \int^{1} \sum_{i=1}^{n} \frac{c_{i n}^{l}}{c_{n i}^{l}}\right)$, there are incomplete elements in the formula, so it can't be used to solve for the sorting vector directly. Auxiliary matrix $\bar{C}^{l}=\left(\bar{c}_{i j}^{l}\right)_{n \times n}$ is constructed for getting the sorting vector $W^{l}=\left(w_{1}^{l}, w_{2}^{l}, \ldots, w_{n}^{l}\right)$ as follows:

$$
\bar{c}_{i j}^{l}= \begin{cases}c_{i j}, & \mathrm{c}_{i j}^{l} \neq \mathrm{x} \\ \frac{w_{i}}{w_{i}+w_{j}}, & \mathbf{c}_{i j}^{l}=\mathbf{x}\end{cases}
$$

Then introduce the deviation term:

$$
\varepsilon_{j}=w_{j}^{l}-1 / \sum_{i=1}^{n} \frac{\bar{c}_{i j}^{l}}{\bar{c}_{j i}^{l}}
$$

Obviously, the choice of the sorting vector of $C^{l}$ should make the deviation function as small as possible, so the following model can be obtained:

$$
\left\{\begin{array}{c}
\min F(w)=\sum_{j=1}^{n}\left(w_{j}^{l}-1 / \sum_{i=1}^{n} \frac{\bar{c}_{i j}^{l}}{\bar{c}_{j i}^{l}}\right)^{2} \\
\text { s.t. } \mathrm{w}_{j} \geq 0, j \in N, \sum_{j=1}^{n} w_{j}=1
\end{array}\right.
$$

Obviously, by solving the model (19), the sorting vector $W^{l}=\left(w_{1}^{l}, w_{2}^{l}, \ldots, w_{n}^{l}\right)$ of the incomplete complementary judgment matrix $C^{l}$ can be obtained. Due to the model is more troublesome, so it can be solved by using the LINGO software. After obtaining the sorting vector of each expert, the sorting vector of the expert group $\mathrm{V}=\left(\mathrm{V}_{1}, \mathrm{~V}_{2} \cdots \mathrm{V}_{\mathrm{n}}\right)$ can be determined by the Eq. (20), which is constructed as follows: 


$$
w_{j}=\sum_{i=1}^{m} w_{i} w_{j}^{l}, j=1,2 \cdots n
$$

Finally, the ranking of agent $\mathrm{Y}$ is determined according to the sorting vector of the expert group.

Using the method of (III), the ordinal value vector $R_{i}=\left(r_{i}, r_{i 2} \cdots r_{i n}\right)$ that the side $Y$ given by the side $X$ is obtained. Similarly, when the preference information given by cloud manufacturing resources about cloud manufacturing tasks is the incomplete complementary judgment matrix, method (III) can be used to obtain the order vector $T_{j}=\left(t_{1 j}, t_{2 j} \cdots t_{m j}\right)$ of cloud manufacturing resources to cloud manufacturing tasks.

\section{2 Construction of the two-sided matching model}

Let $\alpha_{i j}$ be the satisfaction of the side $\mathrm{Y}$ given by the $\mathrm{X}_{\mathrm{i}}$ of side $\mathrm{X}$ and $\beta_{\mathrm{ij}}$ be the satisfaction of the side $\mathrm{X}$ given by the $Y_{j}$ of side $Y$, then $\alpha_{i j}$ and $\beta_{i j}$ can be expressed as $\alpha_{i j}=f\left(r_{i j}\right), \beta_{i j}=g\left(t_{i j}\right)$, where $f(x)$ and $g(x)$ are monotonically decreasing functions and called satisfaction function of agents. (Li et al. 2012; Sun et al. 2017) Therefore, this paper constructs the following satisfaction function:

$f(x)=g(x)=x^{\delta}, x \in[1,+\infty), \delta \in(-\infty, 0)$, then it satisfies the following properties:

(1) $0<f(x) \leqslant 1, x \in[1,+\infty)$;

(2) $f(x)$ is a monotonically decreasing concave function on $[1,+\infty)$;

(3) When the independent variable $\mathrm{x}$ is fixed, $\mathrm{F}$ is a monotonically increasing function of parameter $\delta$.

In this paper, $\mathrm{R}_{\mathrm{i}}$ and $\mathrm{T}_{\mathrm{j}}$ can be used to obtain the satisfaction matrix at time $\mathrm{t}_{1}$ and time $\mathrm{t} 2$. At the same time, considering the influence of information at different times on the final decision, the weight at different times will be used to construct the comprehensive satisfaction matrix of bilateral matching subjects, as shown below:

$$
\begin{aligned}
& \alpha_{i j}=\sum_{k=1}^{p} w\left(t_{k}\right) \times \alpha_{i j}^{t_{k}} \\
& \beta_{i j}=\sum_{k=1}^{p} w\left(t_{k}\right) \times \beta_{i j}^{t_{k}}
\end{aligned}
$$

Let $\mathrm{x}_{\mathrm{ij}}$ be a 0-1 variable. When $\mathrm{x}_{\mathrm{ij}}=0$, it means that the agents $\mathrm{m}_{\mathrm{i}}$ and $\mathrm{n}_{\mathrm{j}}$ do not match; when $\mathrm{x}_{\mathrm{ij}}=1$, it means that the agents $m_{i}$ and $n_{j}$ match. With the goal of maximizing the satisfaction of two-sided agents and minimizing the the sum of the deviations of two-sided matching subjects' satisfaction, a two-sided matching optimization model is established:

$$
\begin{aligned}
& \max Z_{1}=\sum_{i=1}^{m} \sum_{j=1}^{n}\left(\alpha_{i j}+\beta_{i j}\right) x_{i j} \\
& \min Z_{2}=\sum_{i=1}^{m} \sum_{j=1}^{n}\left|\alpha_{i j}-\beta_{i j}\right| x_{i j} \\
& \text { s. t. } \quad \sum_{j=1}^{n} x_{i j}=1, i=1,2 \cdots m \\
& \sum_{i=1}^{m} x_{i j}=1, j=1,2 \cdots n \\
& x_{i j}+\sum_{k: x_{i k}<\alpha_{i j}} x_{i k}+\sum_{\beta t_{i j}<t_{j j}} x_{l j} \geq 1, i=1 \cdots m, j=1,2 \cdots n \\
& \sum_{i=1}^{m} \sum_{j=1}^{n} x_{i j}=\min (m, n), \quad x_{i j} \in\{0,1\}, i=1,2 \cdots m, j=1,2 \cdots n
\end{aligned}
$$

In the above model, the meaning of model (23) is to maximize the total satisfaction of two-sided matching 
subjects as much as possible, and model (24) expresses the fairness of two-sided matching. model (25) means that each $X_{i}$ matches at most one $Y_{j}$. model (26) means that each $Y_{j}$ matches at most one $X_{i}$. model (27) represents the constraint condition of stable matching. model (28) expresses the constraint condition of the number of two-sided matches.

\section{3 Solution to the two-sided matching model}

In the model (23), (24), the objective function has the same dimension and scale, the matching competition of two subjects is used to transform them into a single objective programming model using linear weighting:

$$
\begin{aligned}
& \max Z=\sum_{i=1}^{m} \sum_{j=1}^{n}\left[W_{x}\left(\alpha_{i j}+\beta_{i j}\right)-W_{v}\left|\alpha_{i j}-\beta_{i j}\right|\right] x_{i j} \\
& \text { s. t. } \quad \sum_{j=1}^{n} x_{i j}=1, i=1,2 \cdots m \\
& \sum_{i=1}^{m} x_{i j}=1, j=1,2 \cdots n \\
& x_{i j}+\sum_{k: a_{i k}<\alpha_{i j}} x_{i k}+\sum_{l: p_{j j}<\beta_{i j}} x_{l j} \geq 1, i=1 \cdots m, j=1,2 \cdots n \\
& \sum_{i=1}^{m} \sum_{j=1}^{n} x_{i j}=\min (m, n), \quad x_{i j} \in\{0,1\}, i=1,2 \cdots m, j=1,2 \cdots n
\end{aligned}
$$

$W_{x}$ and $W_{v}$ are the matching competition degrees of two-sided matching subjects respectively.

$$
\begin{aligned}
& W_{x}=\frac{n}{m+n} \\
& W_{v}=\frac{m}{m+n}
\end{aligned}
$$

Scarce resources have stronger competitiveness. In two-sided matching, the one with fewer resources occupies the dominant position. When $\mathrm{m}>\mathrm{n}$, the side of $\mathrm{Y}$ is dominant, and $\mathrm{W}_{\mathrm{x}}<\mathrm{W}_{\mathrm{y}}$; When $\mathrm{m}<\mathrm{n}$, the side of $\mathrm{X}$ is dominant, and $\mathrm{W}_{\mathrm{x}}>\mathrm{W}_{\mathrm{y}}$. When $\mathrm{m}=\mathrm{n}$, both sides are in the same position and $\mathrm{W}_{\mathrm{x}}=\mathrm{W}_{\mathrm{y}}$.

In summary, the calculation steps of the two-sided matching method with uncertain preference order, uncertain linguistic variables and incomplete complementary judgment matrix form preference information are as follows:

Step 1: According to (I)-(III), the uncertain preference order, uncertain linguistic variables and incomplete complementary judgment matrix form preference information given by the two-sided matching subjects are transformed into ordinal value vector $\mathrm{Ri}$ and $\mathrm{T}_{\mathrm{j}}$.

Step 2: Calculate the satisfaction $\alpha_{\mathrm{ij}}$ and $\beta_{\mathrm{ij}}$ of the two-sided matching subjects.

Step 3: Establish the two-sided matching optimization model.

Step 4: Use the linear weighting method to transform the model (23)-(28) into the model (29)-(35), and solve the model to obtain the two-sided matching scheme.

\section{Illustrative example}

To elaborate on this process, the specific implementation process is below. process is below. The cloud manufacturing platform receives 5 cloud manufacturing tasks that need to be outsourced, let $X=\left\{x_{1}, x_{2}, x_{3}, x_{4}\right.$, $\mathrm{X}_{5}$ \} represents the set of the cloud manufacturing tasks. And the 5 cloud manufacturing resources in the cloud manufacturing platform can provide corresponding manufacturing services. let $\mathrm{Y}=\left\{\mathrm{y}_{1}, \mathrm{y}_{2}, \mathrm{y}_{3}, \mathrm{y}_{4}, \mathrm{y}_{5}\right\}$ 
represents the one of the cloud manufacturing resources. Cloud manufacturing tasks mainly conduct comprehensive evaluation of cloud manufacturing resources from the overall situation of product quality, supply capacity, product prices, and service levels. Cloud manufacturing resources comprehensively evaluate the overall situation of cloud manufacturing tasks with reference to technical complexity and production costs. On the other hand, in the actual matching process, due to the differences in the research background, knowledge and experience of decision makers, decision makers can assign different weights to experts to ensure the objectivity and accuracy of the evaluation. Expert weight $\mathrm{w}$ is usually provided by the manager or organizer, and the weight is determined based on consideration of the authority and status of each expert. In this paper, the cloud manufacturing platform makes comprehensive decisions on cloud manufacturing tasks and cloud manufacturing resource preference information based on the evaluation information of multiple preference forms given by three experts. The experts are shown in $E=\left\{\mathrm{e}_{1}, \mathrm{e}_{2}, \mathrm{e}_{3}\right\}$, and the weight vector of the experts are represented as $\mathrm{W}=\{0.2,0.3,0.5\}$. Then through expert analysis, the evaluation matrix of preference information about cloud manufacturing resources given by cloud manufacturing tasks at different times $\mathrm{T}=\left\{\mathrm{t}_{1}, \mathrm{t}_{2}\right\}$ that is shown in Table 1-6 can be obtained. Similarly, the evaluation matrix of preference information about cloud manufacturing resources given by cloud manufacturing tasks at different times $\mathrm{T}=$ $\left\{\mathrm{t}_{1}, \mathrm{t}_{2}\right\}$ that represented as Table 1-12 can be obtained.

Table 1 preference information about cloud manufacturing resources given by $e_{1}$ at $t_{1}$ for cloud manufacturing tasks

\begin{tabular}{|c|c|c|c|c|c|}
\hline $\mathrm{e}_{1}$ & $\mathrm{Y}_{1}$ & $\mathrm{Y}_{2}$ & $\mathrm{Y}_{3}$ & $\mathrm{Y}_{4}$ & $\mathrm{Y}_{5}$ \\
\hline $\mathrm{X}_{1}$ & {$[1,3]$} & {$[2,5]$} & {$[3,4]$} & {$[4,5]$} & {$[2,4]$} \\
\hline $\mathrm{X}_{2}$ & {$\left[\mathrm{~S}_{0}, \mathrm{~S}_{3}\right]$} & {$\left[\mathrm{S}_{1}, \mathrm{~S}_{4}\right]$} & {$\left[\mathrm{S}_{4}, \mathrm{~S}_{5}\right]$} & {$\left[\mathrm{S}_{3}, \mathrm{~S}_{6}\right]$} & {$\left[\mathrm{S}_{2}, \mathrm{~S}_{4}\right]$} \\
\hline $\mathrm{X}_{3}$ & {$[2,5]$} & {$[1,3]$} & {$[3,4]$} & {$[1,4]$} & {$[1,2]$} \\
\hline $\mathrm{X}_{4}$ & {$\left[\mathrm{~S}_{6}, \mathrm{~S}_{2}\right]$} & {$\left[\mathrm{S}_{3}, \mathrm{~S}_{4}\right]$} & {$\left[\mathrm{S}_{4}, \mathrm{~S}_{6}\right]$} & {$\left[\mathrm{S}_{1}, \mathrm{~S}_{3}\right]$} & {$\left[\mathrm{S}_{5}, \mathrm{~S}_{6}\right]$} \\
\hline
\end{tabular}

$$
P_{x 5}=\left[\begin{array}{ccccc}
0.5 & 0.7 & 0.4 & 0.6 & 0.3 \\
0.3 & 0.5 & 0.8 & 0.7 & 0.5 \\
0.6 & 0.2 & 0.5 & x & 0.4 \\
0.4 & 0.3 & 1-x & 0.5 & 0.8 \\
0.7 & 0.5 & 0.6 & 0.2 & 0.5
\end{array}\right]
$$

$$
\min F\left(w_{x 5}\right)=\left(w_{1}-\frac{14}{83}\right)^{2}+\left(w_{2}-\frac{84}{421}\right)^{2}+\left(w_{3}-\frac{1}{\frac{43}{6}+\frac{w_{4}}{w_{3}}}\right)^{2}+\left(w_{4}-\frac{1}{\frac{61}{12}+\frac{w_{3}}{w_{4}}}\right)^{2}+\left(w_{5}-\frac{21}{149}\right)^{2}
$$

Table 2 preference information about cloud manufacturing resources given by $e_{2}$ at $t_{1}$ for cloud manufacturing tasks

\begin{tabular}{|c|c|c|c|c|c|}
\hline $\mathrm{e}_{2}$ & $\mathrm{Y}_{1}$ & $\mathrm{Y}_{2}$ & $\mathrm{Y}_{3}$ & $\mathrm{Y}_{4}$ & $\mathrm{Y}_{5}$ \\
\hline $\mathrm{X}_{1}$ & {$[1,2]$} & {$[3,4]$} & {$[2,5]$} & {$[4,5]$} & {$[2,4]$} \\
\hline $\mathrm{X}_{2}$ & {$\left[\mathrm{~S}_{2}, \mathrm{~S}_{4}\right]$} & {$\left[\mathrm{S}_{1}, \mathrm{~S}_{2}\right]$} & {$\left[\mathrm{S}_{0}, \mathrm{~S}_{3}\right]$} & {$\left[\mathrm{S}_{2}, \mathrm{~S}_{3}\right]$} & {$\left[\mathrm{S}_{0}, \mathrm{~S}_{1}\right]$} \\
\hline $\mathrm{X}_{3}$ & {$[1,4]$} & {$[3,5]$} & {$[2,4]$} & {$[1,3]$} & {$[2,3]$} \\
\hline $\mathrm{X}_{4}$ & {$\left[\mathrm{~S}_{3}, \mathrm{~S}_{4}\right]$} & {$\left[\mathrm{S}_{4}, \mathrm{~S}_{5}\right]$} & {$\left[\mathrm{S}_{2}, \mathrm{~S}_{3}\right]$} & {$\left[\mathrm{S}_{1}, \mathrm{~S}_{2}\right]$} & {$\left[\mathrm{S}_{4}, \mathrm{~S}_{6}\right]$} \\
\hline \multicolumn{5}{|c}{} \\
$P_{x 5}=\left[\begin{array}{ccccc}0.5 & 0.8 & x & 0.4 & 0.7 \\
0.2 & 0.5 & 0.6 & 0.8 & 0.3 \\
1-x & 0.4 & 0.5 & x & 0.8 \\
0.6 & 0.2 & 1-x & 0.5 & 0.2 \\
0.3 & 0.7 & 0.2 & 0.8 & 0.5\end{array}\right]$
\end{tabular}

$$
\min F\left(w_{x 5}\right)=\left(w_{1}-\frac{1}{\frac{89}{28}+\frac{w_{3}}{w_{1}}}\right)^{2}+\left(w_{2}-\frac{4}{33}\right)^{2}+\left(w_{3}-\frac{1}{\frac{11}{4}+\frac{w_{1}+w_{4}}{w_{3}}}\right)^{2}+\left(w_{4}-\frac{1}{\frac{29}{3}+\frac{w_{3}}{w_{4}}}\right)^{2}+\left(w_{5}-\frac{84}{673}\right)^{2}
$$


Table 3 preference information about cloud manufacturing resources given by $e_{3}$ at $t_{1}$ for cloud manufacturing tasks

\begin{tabular}{|c|c|c|c|c|c|}
\hline $\mathrm{e}_{3}$ & $\mathrm{Y}_{1}$ & $\mathrm{Y}_{2}$ & $\mathrm{Y}_{3}$ & $\mathrm{Y}_{4}$ & $\mathrm{Y}_{5}$ \\
\hline $\mathrm{X}_{1}$ & {$[2,4]$} & {$[1,3]$} & {$[4,5]$} & {$[2,3]$} & {$[3,5]$} \\
\hline $\mathrm{X}_{2}$ & {$\left[\mathrm{~S}_{3}, \mathrm{~S}_{5}\right]$} & {$\left[\mathrm{S}_{0}, \mathrm{~S}_{2}\right]$} & {$\left[\mathrm{S}_{1}, \mathrm{~S}_{3}\right]$} & {$\left[\mathrm{S}_{4}, \mathrm{~S}_{6}\right]$} & {$\left[\mathrm{S}_{2}, \mathrm{~S}_{5}\right]$} \\
\hline $\mathrm{X}_{3}$ & {$[2,3]$} & {$[3,4]$} & {$[1,3]$} & {$[3,5]$} & {$[2,4]$} \\
\hline $\mathrm{X}_{4}$ & {$\left[\mathrm{~S}_{1}, \mathrm{~S}_{2}\right]$} & {$\left[\mathrm{S}_{3}, \mathrm{~S}_{5}\right]$} & {$\left[\mathrm{S}_{4}, \mathrm{~S}_{6}\right]$} & {$\left[\mathrm{S}_{0}, \mathrm{~S}_{3}\right]$} & {$\left[\mathrm{S}_{2}, \mathrm{~S}_{4}\right]$} \\
\hline
\end{tabular}

$$
P_{x 5}=\left[\begin{array}{ccccc}
0.5 & 0.4 & x & 0.8 & 0.5 \\
0.6 & 0.5 & 0.8 & x & 0.3 \\
1-x & 0.2 & 0.5 & 0.6 & x \\
0.2 & 1-x & 0.4 & 0.5 & 0.7 \\
0.5 & 0.7 & 1-x & 0.3 & 0.5
\end{array}\right]
$$

$\min F\left(w_{x 5}\right)=\left(w_{1}-\frac{1}{\frac{15}{4}+\frac{w_{3}}{w_{1}}}\right)^{2}+\left(w_{2}-\frac{1}{\frac{17}{4}+\frac{w_{4}}{w_{2}}}\right)^{2}+\left(w_{3}-\frac{1}{\frac{17}{3}+\frac{w_{1}+w_{5}}{w_{3}}}\right)^{2}+\left(w_{4}-\frac{1}{\frac{97}{14}+\frac{w_{2}}{w_{4}}}\right)^{2}+\left(w_{1}-\frac{1}{\frac{100}{21}+\frac{w_{3}}{w_{5}}}\right)^{2}$

Table 4 preference information about cloud manufacturing resources given by $e_{1}$ at $t_{2}$ for cloud manufacturing tasks

\begin{tabular}{|c|c|c|c|c|c|}
\hline $\mathrm{e}_{1}$ & $\mathrm{Y}_{1}$ & $\mathrm{Y}_{2}$ & $\mathrm{Y}_{3}$ & $\mathrm{Y}_{4}$ & $\mathrm{Y}_{5}$ \\
\hline $\mathrm{X}_{1}$ & {$[3,4]$} & {$[2,5]$} & {$[1,2]$} & {$[2,4]$} & {$[4,5]$} \\
\hline $\mathrm{X}_{2}$ & {$\left[\mathrm{~S}_{0}, \mathrm{~S}_{3}\right]$} & {$\left[\mathrm{S}_{3}, \mathrm{~S}_{5}\right]$} & {$\left[\mathrm{S}_{4}, \mathrm{~S}_{6}\right]$} & {$\left[\mathrm{S}_{2}, \mathrm{~S}_{3}\right]$} & {$\left[\mathrm{S}_{2}, \mathrm{~S}_{4}\right]$} \\
\hline $\mathrm{X}_{3}$ & {$[1,3]$} & {$[2,3]$} & {$[3,5]$} & {$[4,5]$} & {$[2,4]$} \\
\hline $\mathrm{X}_{4}$ & {$\left[\mathrm{~S}_{2}, \mathrm{~S}_{3}\right]$} & {$\left[\mathrm{S}_{4}, \mathrm{~S}_{6}\right]$} & {$\left[\mathrm{S}_{0}, \mathrm{~S}_{2}\right]$} & {$\left[\mathrm{S}_{5}, \mathrm{~S}_{6}\right]$} & {$\left[\mathrm{S}_{1}, \mathrm{~S}_{3}\right]$} \\
\hline
\end{tabular}

$$
P_{x 5}=\left[\begin{array}{ccccc}
0.5 & 0.6 & 0.8 & x & 0.7 \\
0.4 & 0.5 & 0.8 & 0.4 & 0.6 \\
0.2 & 0.2 & 0.5 & 0.9 & 0.8 \\
1-x & 0.6 & 0.1 & 0.5 & 0.2 \\
0.3 & 0.4 & 0.2 & 0.8 & 0.5
\end{array}\right]
$$

$\min F\left(w_{x 5}\right)=\left(w_{1}-\frac{1}{\frac{197}{84}+\frac{w_{4}}{w_{1}}}\right)^{2}+\left(w_{2}-\frac{12}{59}\right)^{2}+\left(w_{3}-\frac{36}{337}\right)^{2}+\left(w_{4}-\frac{1}{\frac{44}{3}+\frac{w_{1}}{w_{4}}}\right)^{2}+\left(w_{5}-\frac{12}{109}\right)^{2}$

Table 5 preference information about cloud manufacturing resources given by $\mathrm{e}_{2}$ at $\mathrm{t}_{2}$ for cloud manufacturing tasks

\begin{tabular}{|c|c|c|c|c|c|}
\hline $\mathrm{e}_{2}$ & $\mathrm{Y}_{1}$ & $\mathrm{Y}_{2}$ & $\mathrm{Y}_{3}$ & $\mathrm{Y}_{4}$ & $\mathrm{Y}_{5}$ \\
\hline $\mathrm{X}_{1}$ & {$[1,2]$} & {$[4,5]$} & {$[3,4]$} & {$[3,5]$} & {$[1,3]$} \\
\hline $\mathrm{X}_{2}$ & {$\left[\mathrm{~S}_{1}, \mathrm{~S}_{3}\right]$} & {$\left[\mathrm{S}_{0}, \mathrm{~S}_{2}\right]$} & {$\left[\mathrm{S}_{5}, \mathrm{~S}_{6}\right]$} & {$\left[\mathrm{S}_{3}, \mathrm{~S}_{5}\right]$} & {$\left[\mathrm{S}_{2}, \mathrm{~S}_{4}\right]$} \\
\hline $\mathrm{X}_{3}$ & {$[2,4]$} & {$[3,5]$} & {$[3,4]$} & {$[2,3]$} & {$[1,2]$} \\
\hline $\mathrm{X}_{4}$ & {$\left[\mathrm{~S}_{4}, \mathrm{~S}_{6}\right]$} & {$\left[\mathrm{S}_{0}, \mathrm{~S}_{3}\right]$} & {$\left[\mathrm{S}_{1}, \mathrm{~S}_{2}\right]$} & {$\left[\mathrm{S}_{3}, \mathrm{~S}_{5}\right]$} & {$\left[\mathrm{S}_{2}, \mathrm{~S}_{4}\right]$} \\
\hline
\end{tabular}

$$
P_{x 5}=\left[\begin{array}{ccccc}
0.5 & x & 0.6 & 0.3 & 0.8 \\
1-x & 0.5 & x & x & 0.6 \\
0.4 & 1-x & 0.5 & 0.7 & 0.8 \\
0.7 & 1-x & 0.3 & 0.5 & x \\
0.2 & 0.4 & 0.2 & 1-x & 0.5
\end{array}\right]
$$




$$
\min F\left(w_{x 5}\right)=\left(w_{1}-\frac{1}{\frac{17}{4}+\frac{w_{2}}{w_{1}}}\right)^{2}+\left(w_{2}-\frac{1}{\frac{5}{3}+\frac{w_{1}+w_{3}+w_{4}}{w_{4}}}\right)^{2}+\left(w_{3}-\frac{1}{\frac{89}{28}+\frac{w_{2}}{w_{3}}}\right)^{2}+\left(w_{4}-\frac{1}{\frac{79}{21}+\frac{w_{2}+w_{5}}{w_{4}}}\right)^{2}+\left(w_{5}-\frac{1}{\frac{21}{2}+\frac{w_{4}}{w_{5}}}\right)^{2}
$$

Table 6 preference information about cloud manufacturing resources given by $e_{3}$ at $t_{2}$ for cloud manufacturing tasks

\begin{tabular}{|c|c|c|c|c|c|}
\hline $\mathrm{e}_{3}$ & $\mathrm{Y}_{1}$ & $\mathrm{Y}_{2}$ & $\mathrm{Y}_{3}$ & $\mathrm{Y}_{4}$ & $\mathrm{Y}_{5}$ \\
\hline $\mathrm{X}_{1}$ & {$[2,5]$} & {$[1,4]$} & {$[1,3]$} & {$[4,5]$} & {$[3,4]$} \\
\hline $\mathrm{X}_{2}$ & {$\left[\mathrm{~S}_{1}, \mathrm{~S}_{2}\right]$} & {$\left[\mathrm{S}_{3}, \mathrm{~S}_{6}\right]$} & {$\left[\mathrm{S}_{0}, \mathrm{~S}_{3}\right]$} & {$\left[\mathrm{S}_{2}, \mathrm{~S}_{4}\right]$} & {$\left[\mathrm{S}_{4}, \mathrm{~S}_{5}\right]$} \\
\hline $\mathrm{X}_{3}$ & {$[1,2]$} & {$[2,3]$} & {$[3,5]$} & {$[2,4]$} & {$[3,5]$} \\
\hline $\mathrm{X}_{4}$ & {$\left[\mathrm{~S}_{4}, \mathrm{~S}_{6}\right]$} & {$\left[\mathrm{S}_{0}, \mathrm{~S}_{3}\right]$} & {$\left[\mathrm{S}_{1}, \mathrm{~S}_{3}\right]$} & {$\left[\mathrm{S}_{5}, \mathrm{~S}_{6}\right]$} & {$\left[\mathrm{S}_{2}, \mathrm{~S}_{4}\right]$} \\
\hline
\end{tabular}

$$
P_{x 5}=\left[\begin{array}{ccccc}
0.5 & 0.7 & 0.7 & x & 0.8 \\
0.3 & 0.5 & x & 0.6 & 0.5 \\
0.3 & 1-x & 0.5 & 0.4 & x \\
1-x & 0.4 & 0.6 & 0.5 & 0.3 \\
0.2 & 0.5 & 1-x & 0.7 & 0.5
\end{array}\right]
$$

$\min F\left(w_{x 5}\right)=\left(w_{1}-\frac{28 w_{1}}{28 w_{4}+59 w_{1}}\right)^{2}+\left(w_{2}-\frac{w_{2}}{5 w_{2}+w_{3}}\right)^{2}+\left(w_{3}-\frac{6 w_{3}}{6 w_{2}+6 w_{5}+29 w_{3}}\right)^{2}+\left(w_{4}-\frac{2 w_{4}}{2 w_{1}+11 w_{4}}\right)^{2}+\left(w_{5}-\frac{7 w_{5}}{7 w_{3}+45 w_{5}}\right)^{2}$

Table 7 preference information about cloud manufacturing tasks given by $e_{1}$ at $t_{1}$ for cloud manufacturing resources

\begin{tabular}{|c|c|c|c|c|c|}
\hline $\mathrm{e}_{1}$ & $\mathrm{X}_{1}$ & $\mathrm{X}_{2}$ & $\mathrm{X}_{3}$ & $\mathrm{X}_{4}$ & $\mathrm{X}_{5}$ \\
\hline $\mathrm{Y}_{1}$ & {$[2,4]$} & {$[1,3]$} & {$[3,5]$} & {$[2,5]$} & {$[3,4]$} \\
\hline $\mathrm{Y}_{2}$ & {$\left[\mathrm{~S}_{0}, \mathrm{~S}_{3}\right]$} & {$\left[\mathrm{S}_{1}, \mathrm{~S}_{4}\right]$} & {$\left[\mathrm{S}_{3}, \mathrm{~S}_{6}\right]$} & {$\left[\mathrm{S}_{2}, \mathrm{~S}_{3}\right]$} & {$\left[\mathrm{S}_{5}, \mathrm{~S}_{6}\right]$} \\
\hline $\mathrm{Y}_{5}$ & {$[1,3]$} & {$[2,3]$} & {$[2,5]$} & {$[1,2]$} & {$[3,5]$} \\
\hline & $P_{x 3}=\left[\begin{array}{ccccc}0.5 & 0.7 & 0.5 & 1-x & 0.6 \\
0.3 & 0.5 & 0.8 & 0.7 & 0.4 \\
0.5 & 0.2 & 0.5 & 0.6 & 0.3 \\
x & 0.3 & 0.4 & 0.5 & x \\
0.4 & 0.6 & 0.7 & 1-x & 0.5\end{array}\right] P_{x 4}=\left[\begin{array}{ccccc}0.5 & 0.4 & 0.8 & 0.7 & 0.6 \\
0.6 & 0.5 & 1-x & 0.2 & 0.7 \\
0.2 & x & 0.5 & x & 0.6 \\
0.3 & 0.8 & 1-x & 0.5 & 0.2 \\
0.4 & 0.3 & 0.4 & 0.8 & 0.5\end{array}\right]$
\end{tabular}

$\min F\left(w_{x 3}\right)=\left(w_{1}-\frac{21 w_{1}}{21 w_{4}+65 w_{1}}\right)^{2}+\left(w_{2}-\frac{84}{463}\right)^{2}+\left(w_{3}-\frac{1}{9}\right)^{2}+\left(w_{4}-\frac{6 w_{4}}{6 w_{1}+6 w_{5}+29 w_{4}}\right)^{2}+\left(w_{5}-\frac{42 w_{5}}{42 w_{4}+151 w_{5}}\right)^{2}$ $\min F\left(w_{x 4}\right)=\left(w_{1}-\frac{84}{323}\right)^{2}+\left(w_{2}-\frac{21 w_{2}}{21 w_{3}+2688}\right)^{2}+\left(w_{3}-\frac{3 w_{3}}{3 w_{3}+3 w_{4}+17 w_{3}}\right)^{2}+\left(w_{4}-\frac{12 w_{4}}{12 w_{3}+91 w_{4}}\right)^{2}+\left(w_{5}-\frac{12}{79}\right)^{2}$

Table 8 preference information about cloud manufacturing tasks given by $\mathrm{e}_{2}$ at $\mathrm{t}_{1}$ for cloud manufacturing resources

\begin{tabular}{|c|c|c|c|c|c|}
\hline $\mathrm{e}_{2}$ & $\mathrm{X}_{1}$ & $\mathrm{X}_{2}$ & $\mathrm{X}_{3}$ & $\mathrm{X}_{4}$ & $\mathrm{X}_{5}$ \\
\hline $\mathrm{Y}_{1}$ & {$[3,4]$} & {$[4,5]$} & {$[2,3]$} & {$[4,5]$} & {$[1,4]$} \\
\hline $\mathrm{Y}_{2}$ & {$\left[\mathrm{~S}_{3}, \mathrm{~S}_{5}\right]$} & {$\left[\mathrm{S}_{1}, \mathrm{~S}_{4}\right]$} & {$\left[\mathrm{S}_{0}, \mathrm{~S}_{2}\right]$} & {$\left[\mathrm{S}_{5}, \mathrm{~S}_{6}\right]$} & {$\left[\mathrm{S}_{4}, \mathrm{~S}_{6}\right]$} \\
\hline $\mathrm{Y}_{5}$ & {$[2,4]$} & {$[4,5]$} & {$[1,3]$} & {$[2,4]$} & {$[2,3]$} \\
\hline
\end{tabular}

$P_{x 3}=\left[\begin{array}{ccccc}0.5 & 0.6 & 0.3 & 0.4 & 0.7 \\ 0.4 & 0.5 & x & 0.2 & x \\ 0.7 & 1-x & 0.5 & 0.7 & 0.3 \\ 0.6 & 0.8 & 0.3 & 0.5 & 0.6 \\ 0.3 & 1-x & 0.7 & 0.4 & 0.5\end{array}\right] P_{x 4}=\left[\begin{array}{ccccc}0.5 & 0.7 & 0.2 & 0.5 & 0.8 \\ 0.3 & 0.5 & 1-x & 0.4 & 0.3 \\ 0.8 & x & 0.5 & 1-x & 0.7 \\ 0.5 & 0.6 & x & 0.5 & 1-x \\ 0.2 & 0.7 & 0.3 & x & 0.5\end{array}\right]$


$\min F\left(w_{x 3}\right)=\left(w_{1}-\frac{14}{83}\right)^{2}+\left(w_{2}-\frac{42 w_{2}}{42 w_{3}+263 w_{2}}\right)^{2}+\left(w_{3}-\frac{21 w 3}{21 w 2+88 w 3}\right)^{2}+\left(w_{4}-\frac{12}{59}\right)^{2}+\left(w_{5}-\frac{42 w_{5}}{42 w_{2}+221 w_{5}}\right)^{2}$ $\min F\left(w_{x 4}\right)=\left(w_{1}-\frac{28}{187}\right)^{2}+\left(w_{2}-\frac{6 w_{2}}{6 w_{3}+43 w_{2}}\right)^{2}+\left(w_{3}-\frac{28 w_{3}}{28 w_{2}+28 w_{4}+47 w_{3}}\right)^{2}+\left(w_{4}-\frac{3 w_{4}}{3 w_{3}+3 w_{5}+8 w_{4}}\right)^{2}+\left(w_{5}-\frac{21 w_{5}}{21 w_{4}+163 w_{5}}\right)^{2}$

Table 9 preference information about cloud manufacturing tasks given by $e_{3}$ at $t_{1}$ for cloud manufacturing resources

\begin{tabular}{|c|c|c|c|c|c|}
\hline $\mathrm{e}_{3}$ & $\mathrm{X}_{1}$ & $\mathrm{X}_{2}$ & $\mathrm{X}_{3}$ & $\mathrm{X}_{4}$ & $\mathrm{X}_{5}$ \\
\hline $\mathrm{Y}_{1}$ & {$[3,4]$} & {$[1,3]$} & {$[2,4]$} & {$[3,5]$} & {$[4,5]$} \\
\hline $\mathrm{Y}_{2}$ & {$\left[\mathrm{~S}_{4}, \mathrm{~S}_{6}\right]$} & {$\left[\mathrm{S}_{3}, \mathrm{~S}_{5}\right]$} & {$\left[\mathrm{S}_{0}, \mathrm{~S}_{3}\right]$} & {$\left[\mathrm{S}_{1}, \mathrm{~S}_{2}\right]$} & {$\left[\mathrm{S}_{2}, \mathrm{~S}_{5}\right]$} \\
\hline $\mathrm{Y}_{5}$ & {$[4,5]$} & {$[3,4]$} & {$[2,3]$} & {$[1,2]$} & {$[3,4]$} \\
\hline
\end{tabular}

$$
P_{x 3}=\left[\begin{array}{ccccc}
0.5 & 0.6 & 0.7 & x & 0.4 \\
0.4 & 0.5 & 0.8 & 1-x & 0.7 \\
0.3 & 0.2 & 0.5 & 0.7 & 0.6 \\
1-x & x & 0.3 & 0.5 & x \\
0.6 & 0.3 & 0.4 & 1-x & 0.5
\end{array}\right] P_{x 4}=\left[\begin{array}{ccccc}
0.5 & 0.7 & 0.6 & x & 0.6 \\
0.3 & 0.5 & 1-x & 0.8 & 0.3 \\
0.4 & x & 0.5 & 0.4 & 1-x \\
1-x & 0.2 & 0.6 & 0.5 & 0.4 \\
0.4 & 0.7 & x & 0.6 & 0.5
\end{array}\right]
$$

$\min F\left(w_{x 3}\right)=\left(w_{1}-\frac{42 w_{1}}{42 w_{4}+151 w_{1}}\right)^{2}+\left(w_{2}-\frac{28 w_{2}}{28 w_{4}+89 w_{2}}\right)^{2}+\left(w_{3}-\frac{7}{59}\right)^{2}+\left(w_{4}-\frac{3 w_{4}}{3 w_{1}+3 w_{2}+3 w_{5}+10 w_{4}}\right)^{2}+\left(w_{5}-\frac{2 w_{5}}{2 w_{4}+11 w_{5}}\right)^{2}$ $\min F\left(w_{x 4}\right)=\left(w_{1}-\frac{21 w 1}{21 w 4+58 w 1}\right)^{2}+\left(w_{2}-\frac{12 w_{2}}{12 w_{3}+71 w_{2}}\right)^{2}+\left(w_{3}-\frac{w_{3}}{w_{2}+w_{5}+w_{3}}\right)^{2}+\left(w_{4}-\frac{6 w_{4}}{6 w_{1}+43 w_{4}}\right)^{2}+\left(w_{5}-\frac{42 w_{5}}{42 w_{3}+6342}\right)^{2}$

Table 10 preference information about cloud manufacturing tasks given by $e_{1}$ at $t_{2}$ for cloud manufacturing resources

\begin{tabular}{|c|c|c|c|c|c|}
\hline $\mathrm{e}_{1}$ & $\mathrm{X}_{1}$ & $\mathrm{X}_{2}$ & $\mathrm{X}_{3}$ & $\mathrm{X}_{4}$ & $\mathrm{X}_{5}$ \\
\hline $\mathrm{Y}_{1}$ & {$[2,3]$} & {$[3,4]$} & {$[2,4]$} & {$[2,5]$} & {$[4,5]$} \\
\hline $\mathrm{Y}_{2}$ & {$\left[\mathrm{~S}_{0}, \mathrm{~S}_{1}\right]$} & {$\left[\mathrm{S}_{4}, \mathrm{~S}_{6}\right]$} & {$\left[\mathrm{S}_{3}, \mathrm{~S}_{5}\right]$} & {$\left[\mathrm{S}_{1}, \mathrm{~S}_{2}\right]$} & {$\left[\mathrm{S}_{3}, \mathrm{~S}_{4}\right]$} \\
\hline $\mathrm{Y}_{5}$ & {$[1,2]$} & {$[1,3]$} & {$[4,5]$} & {$[2,3]$} & {$[2,4]$} \\
\hline
\end{tabular}

$P_{x 3}=\left[\begin{array}{ccccc}0.5 & 0.8 & 0.7 & 1-x & 0.1 \\ 0.2 & 0.5 & x & x & 0.8 \\ 0.3 & 1-x & 0.5 & 0.6 & 0.2 \\ x & 1-x & 0.4 & 0.5 & 0.7 \\ 0.9 & 0.2 & 0.8 & 0.3 & 0.5\end{array}\right] P_{x 4}=\left[\begin{array}{ccccc}0.5 & 0.6 & 0.6 & 0.2 & 0.3 \\ 0.4 & 0.5 & 0.7 & 0.6 & 0.6 \\ 0.4 & 0.3 & 0.5 & 0.8 & 0.4 \\ 0.8 & 0.4 & 0.2 & 0.5 & x \\ 0.7 & 0.4 & 0.6 & 1-x & 0.5\end{array}\right]$

$\min F\left(w_{x 3}\right)=\left(w_{1}-\frac{28 w_{1}}{299 w_{1}+28 w_{4}}\right)^{2}+\left(w_{2}-\frac{4 w_{2}}{21 w_{2}+4 w_{3}+4 w_{4}}\right)^{2}+\left(w_{3}-\frac{w 3}{8 w 3+w 2}\right)^{2}+\left(w_{4}-\frac{14 w_{4}}{14 w_{1}+14 w_{2}+41 w_{4}}\right)^{2}+\left(w_{5}-\frac{36}{277}\right)^{2}$ $\min F\left(w_{x 4}\right)=\left(w_{1}-\frac{3}{26}\right)^{2}+\left(w_{2}-\frac{42}{179}\right)^{2}+\left(w_{3}-\frac{12}{79}\right)^{2}+\left(w_{4}-\frac{4 w_{4}}{4 w_{5}+27 w_{4}}\right)^{2}+\left(w_{5}-\frac{42 w_{5}}{42 w_{4}+151 w_{5}}\right)^{2}$

Table 11 preference information about cloud manufacturing tasks given by $\mathrm{e}_{2}$ at $\mathrm{t}_{2}$ for cloud manufacturing resources

\begin{tabular}{|c|c|c|c|c|c|}
\hline $\mathrm{e}_{2}$ & $\mathrm{X}_{1}$ & $\mathrm{X}_{2}$ & $\mathrm{X}_{3}$ & $\mathrm{X}_{4}$ & $\mathrm{X}_{5}$ \\
\hline $\mathrm{Y}_{1}$ & {$[4,5]$} & {$[3,5]$} & {$[1,2]$} & {$[4,5]$} & {$[1,3]$} \\
\hline $\mathrm{Y}_{2}$ & {$\left[\mathrm{~S}_{1}, \mathrm{~S}_{3}\right]$} & {$\left[\mathrm{S}_{4}, \mathrm{~S}_{6}\right]$} & {$\left[\mathrm{S}_{2}, \mathrm{~S}_{3}\right]$} & {$\left[\mathrm{S}_{2}, \mathrm{~S}_{4}\right]$} & {$\left[\mathrm{S}_{0}, \mathrm{~S}_{3}\right]$} \\
\hline $\mathrm{Y}_{5}$ & {$[1,4]$} & {$[2,5]$} & {$[3,4]$} & {$[3,4]$} & {$[2,3]$} \\
\hline
\end{tabular}




$$
P_{x 3}=\left[\begin{array}{ccccc}
0.5 & 0.8 & 0.2 & 0.7 & 0.6 \\
0.2 & 0.5 & 0.6 & 0.6 & x \\
0.8 & 0.4 & 0.5 & 0.6 & 0.5 \\
0.3 & 0.4 & 0.4 & 0.5 & 1-x \\
0.4 & 1-x & x & 1-x & 0.5
\end{array}\right] P_{x 4}=\left[\begin{array}{ccccc}
0.5 & 0.3 & 1-x & 0.8 & x \\
0.7 & 0.5 & 0.6 & 0.5 & 1-x \\
x & 0.4 & 0.5 & 0.7 & 0.2 \\
0.2 & 0.5 & 0.3 & 0.5 & 0.6 \\
1-x & x & 0.8 & 0.4 & 0.5
\end{array}\right]
$$

$\min F\left(w_{x 3}\right)=\left(w_{1}-\frac{84}{533}\right)^{2}+\left(w_{2}-\frac{3 w_{2}}{19 w_{2}+3 w_{5}}\right)^{2}+\left(w_{3}-\frac{12 w_{3}}{41 w_{3}+12 w_{5}}\right)^{2}+\left(w_{4}-\frac{3 w_{4}}{3 w_{5}+19 w_{4}}\right)^{2}+\left(w_{5}-\frac{2 w_{5}}{7 w_{5}+w_{2}+w_{4}}\right)^{2}$ $\min F\left(w_{x 4}\right)=\left(w_{1}-\frac{12 w_{1}}{43 w_{1}+12 w_{3}+12 w_{5}}\right)^{2}+\left(w_{2}-\frac{21 w_{2}}{65 w_{2}+21 w_{5}}\right)^{2}+\left(w_{3}-\frac{14 w_{3}}{14 w_{1}+97 w_{3}}\right)^{2}+\left(w_{4}-\frac{1}{9}\right)^{2}+\left(w_{5}-\frac{4 w_{5}}{4 w_{1}+11 w_{5}+4 w_{2}}\right)^{2}$

Table 12 preference information about cloud manufacturing tasks given by $e_{3}$ at $t_{2}$ for cloud manufacturing

\begin{tabular}{|c|c|c|c|c|c|}
\hline \multicolumn{7}{|c|}{ resources } \\
\hline $\mathrm{e}_{3}$ & $\mathrm{X}_{1}$ & $\mathrm{X}_{2}$ & $\mathrm{X}_{3}$ & $\mathrm{X}_{4}$ & $\mathrm{X}_{5}$ \\
\hline $\mathrm{Y}_{1}$ & {$[2,3]$} & {$[1,3]$} & {$[3,5]$} & {$[2,5]$} & {$[1,2]$} \\
\hline $\mathrm{Y}_{2}$ & {$\left[\mathrm{~S}_{0}, \mathrm{~S}_{2}\right]$} & {$\left[\mathrm{S}_{3}, \mathrm{~S}_{4}\right]$} & {$\left[\mathrm{S}_{3}, \mathrm{~S}_{5}\right]$} & {$\left[\mathrm{S}_{2}, \mathrm{~S}_{3}\right]$} & {$\left[\mathrm{S}_{5}, \mathrm{~S}_{6}\right]$} \\
\hline $\mathrm{Y}_{5}$ & {$[3,5]$} & {$[4,5]$} & {$[1,3]$} & {$[3,5]$} & {$[2,3]$} \\
\hline
\end{tabular}

$$
P_{x 3}=\left[\begin{array}{ccccc}
0.5 & 0.3 & 0.7 & 1-x & 0.8 \\
0.7 & 0.5 & x & x & 0.7 \\
0.3 & 1-x & 0.5 & 0.6 & 0.3 \\
x & 1-x & 0.4 & 0.5 & 0.8 \\
0.2 & 0.3 & 0.7 & 0.2 & 0.5
\end{array}\right] P_{x 4}=\left[\begin{array}{ccccc}
0.5 & 0.4 & 0.8 & 0.7 & 0.8 \\
0.6 & 0.5 & 0.6 & 1-x & 0.5 \\
0.2 & 0.4 & 0.5 & 1-x & 1-x \\
0.3 & x & x & 0.5 & 0.7 \\
0.2 & 0.5 & x & 0.3 & 0.5
\end{array}\right]
$$

$\min F\left(w_{x 3}\right)=\left(w_{1}-\frac{84 w_{1}}{337 w_{1}+84 w_{3}}\right)^{2}+\left(w_{2}-\frac{7 w_{2}}{13 w_{2}+7 w_{3}+7 w_{4}}\right)^{2}+\left(w_{3}-\frac{3 w_{3}}{19 w_{3}+3 w_{2}}\right)^{2}+\left(w_{4}-\frac{4 w_{4}}{4 w_{1}+4 w_{2}+11 w_{4}}\right)^{2}+\left(w_{5}-\frac{21}{247}\right)^{2}$

$$
\min F\left(w_{x 4}\right)=\left(w_{1}-\frac{7}{24}\right)^{2}+\left(w_{2}-\frac{3 w_{2}}{10 w_{2}+3 w_{4}}\right)^{2}+\left(w_{3}-\frac{2 w_{3}}{13 w_{3}+2 w_{4}+2 w_{5}}\right)^{2}+\left(w_{4}-\frac{21 w_{4}}{79 w_{4}+21 w_{2}+21 w_{3}}\right)^{2}+\left(w_{5}-\frac{3 w_{5}}{25 w_{5}+3 w_{3}}\right)^{2}
$$

In order to solve the above-mentioned two-sided matching problem, the calculation process and results of the above method are given below. After calculation, the ordinal value vectors of cloud manufacturing tasks to cloud manufacturing resources at $\mathrm{t}_{1}$ and $\mathrm{t} 2$ are:

$$
\mathrm{R}_{1}=\left(\mathrm{r}_{1}, \mathrm{r}_{2}, \mathrm{r}_{3}, \mathrm{r}_{4}, \mathrm{r}_{5}\right)=\left[\begin{array}{ccccc}
1 & 3 & 5 & 2 & 4 \\
2 & 5 & 4 & 1 & 3 \\
3 & 4 & 1 & 5 & 2 \\
5 & 3 & 1 & 4 & 2 \\
1 & 2 & 3 & 5 & 4
\end{array}\right] \mathrm{R}_{2}=\left(\mathrm{r}_{1}, \mathrm{r}_{2}, \mathrm{r}_{3}, \mathrm{r}_{4}, \mathrm{r}_{5}\right)=\left[\begin{array}{ccccc}
1 & 3 & 5 & 2 & 4 \\
2 & 5 & 4 & 1 & 3 \\
3 & 4 & 1 & 5 & 2 \\
5 & 3 & 1 & 4 & 2 \\
1 & 2 & 3 & 5 & 4
\end{array}\right]
$$

At $t 1$ and $t 2$, the ordinal value vectors of cloud manufacturing resources to cloud manufacturing tasks are:

$$
\mathrm{T}_{1}=\left(\mathrm{t}_{1}, \mathrm{t}_{2}, \mathrm{t}_{3}, \mathrm{t}_{4}, \mathrm{t}_{5}\right)=\left[\begin{array}{lllll}
4 & 1 & 2 & 5 & 3 \\
2 & 3 & 5 & 4 & 1 \\
2 & 5 & 1 & 4 & 3 \\
3 & 5 & 2 & 1 & 4 \\
5 & 4 & 2 & 1 & 3
\end{array}\right] \mathrm{T}_{2}=\left(\mathrm{t}_{1}, \mathrm{t}_{2}, \mathrm{t}_{3}, \mathrm{t}_{4}, \mathrm{t}_{5}\right)=\left[\begin{array}{lllll}
2 & 3 & 5 & 4 & 1 \\
4 & 1 & 3 & 4 & 2 \\
2 & 4 & 1 & 3 & 5 \\
1 & 2 & 3 & 4 & 5 \\
1 & 5 & 3 & 4 & 2
\end{array}\right]
$$

Calculated by the Eq. (8), let the attenuation coefficient $\lambda=0.5$, the weight at $\mathrm{t}_{1}$ is $w\left(t_{1}\right)=\frac{e^{\frac{1}{2}}\left(1-e^{\frac{1}{2}}\right)}{e^{\frac{1}{2}}\left(1-e^{1}\right)}=0.38$, the weight at $\mathrm{t}_{2}$ is $w\left(t_{2}\right)=\frac{e^{1}\left(1-e^{\frac{1}{2}}\right)}{e^{\frac{1}{2}}\left(1-e^{1}\right)}=0.62$, and the satisfaction function $\mathrm{h}(\mathrm{x})=\mathrm{x}^{-1}, \mathrm{~g}(\mathrm{x})=\mathrm{x}^{-1}$, calculate the 
comprehensive satisfaction of two-sided matching subjects at multiple moments as follows:

$$
\left(\alpha_{i j}\right)_{5 \times 5}=\left[\begin{array}{ccccc}
0.69 & 0.28 & 0.7 & 0.31 & 0.3 \\
0.31 & 0.28 & 0.41 & 0.54 & 0.75 \\
0.75 & 0.3 & 0.54 & 0.39 & 0.31 \\
0.39 & 0.33 & 0.54 & 0.72 & 0.35 \\
1 & 0.39 & 0.44 & 0.23 & 0.22
\end{array}\right] \quad\left(\beta_{i j}\right)_{5 \times 5}=\left[\begin{array}{ccccc}
0.41 & 0.58 & 0.31 & 0.23 & 0.75 \\
0.35 & 0.75 & 0.3 & 0.25 & 0.69 \\
0.5 & 0.23 & 1 & 0.3 & 0.23 \\
0.75 & 0.39 & 0.39 & 0.54 & 0.22 \\
0.7 & 0.22 & 0.39 & 0.54 & 0.44
\end{array}\right]
$$

At this point, according to the Eq. (34)-(35) and the comprehensive satisfaction matrix, construct the value coefficient matrix of the objective function by cloud manufacturing tasks and cloud manufacturing resources,

Among them, the value coefficient of the objective function $C_{i j}=W_{x}\left(\alpha_{i j}+\beta_{i j}\right)-W_{v}\left|\alpha_{i j}-\beta_{i j}\right|$ is as follows:

$$
\left(C_{i j}\right)_{5 \times 5}=\left[\begin{array}{ccccc}
0.41 & 0.33 & 0.2 & 0.23 & 0.75 \\
0.25 & 0.75 & 0.3 & 0.25 & 0.5 \\
0.5 & 0.23 & 1 & 0.3 & 0.2 \\
0.39 & 0.33 & 0.39 & 0.54 & 0.22 \\
0.7 & 0.22 & 0.39 & 0.23 & 0.22
\end{array}\right]
$$

A two-sided matching multi-objective programming model (23)-(28) is established, and the multi-objective programming model is transformed into a single-objective programming model (29)-(35) through the matching competition degree of two-sided matching subjects $W_{x}=\frac{1}{2}, W_{v}=\frac{1}{2}$, as shown in the following:

$$
\begin{gathered}
\max Z=\sum_{i=1}^{5} \sum_{j=1}^{5}\left[\frac{1}{2}\left(\alpha_{i j}+\beta_{i j}\right)-\frac{1}{2}\left|\alpha_{i j}-\beta_{i j}\right|\right] x_{i j} \\
\text { s. t. } \quad \sum_{j=1}^{n} x_{i j}=1, i=1,2 \cdots 5 \\
\sum_{i=1}^{m} x_{i j}=1, j=1,2 \cdots 5 \\
x_{i j}+\sum_{k: x_{i k}<\alpha_{i j}} x_{i k}+\sum_{\beta t_{i j}<i j} x_{i j} \geq 1, i=1, \cdots 5, j=1,2 \cdots 5 \\
\sum_{i=1}^{m} \sum_{j=1}^{n} x_{i j}=\min (m, n), \quad x_{i j} \in\{0,1\}, i=1,2 \cdots 5, j=1,2 \cdots 5
\end{gathered}
$$

This proposed model can be solved by applying the LINGO 18. 0 software. The matching results are as follows:

$$
Z^{*}=1.92, X_{14}=X_{21}=X_{33}=X_{45}=X_{52}=1 \text {, the rest of the } X_{i j}=0 \text {. }
$$

This paper achieves one-to-one two-sided matching between cloud manufacturing tasks and cloud manufacturing resources by constructing the nonlinear programming model to fit the Various forms of preference information. The method in this paper has wider applicability.

\section{Discussions}

\subsection{Matching result analysis}

After obtaining the dynamic two-sided matching results at different times, the discussion on the two-sided matching results at different times was continued, thus illustrating the necessity of dynamic two-sided 
matching between cloud manufacturing tasks and cloud manufacturing resources. In addition, comparative analysis is made and the advantages of the matching model are pointed out. From the previous study, the satisfaction matrix of cloud manufacturing tasks and cloud manufacturing resources at different moments of $t_{k}$ has been obtained. According to the satisfaction matrix, the value coefficient matrix of objective function is constructed respectively, and the corresponding two-sided matching results are solved through the two-sided matching model proposed in this paper. The value coefficient matrix of cloud manufacturing tasks and cloud manufacturing resources at time $t_{1}$ is shown as follows:

$$
C\left(t_{1}\right)=\left(C_{i j}\right)_{5 \times 5}=\left[\begin{array}{ccccc}
0.25 & 0.33 & 0.2 & 0.2 & 0.25 \\
0.5 & 0.2 & 0.2 & 0.25 & 0.33 \\
0.33 & 0.2 & 1 & 0.2 & 0.33 \\
0.2 & 0.2 & 0.5 & 0.25 & 0.25 \\
0.2 & 0.25 & 0.33 & 0.2 & 0.25
\end{array}\right]
$$

Based on this matrix, the matching model proposed in this paper was used to solve the problem, and the target value and matching result of two-sided matching between cloud manufacturing tasks and cloud manufacturing resources at $t_{1}$ are obtained as follows:

$$
\begin{gathered}
\mathrm{Z}\left(\mathrm{t}_{1}\right)^{*}=1.05, \\
\mathrm{X}_{13}=\mathrm{X}_{22}=\mathrm{X}_{34}=\mathrm{X}_{41}=\mathrm{X}_{55}=1 \text {, the rest of the } \mathrm{X}_{\mathrm{ij}}=0 .
\end{gathered}
$$

The value coefficient matrix of cloud manufacturing tasks and cloud manufacturing resources at time $t_{2}$ are as follows:

$$
C\left(t_{2}\right)=\left(C_{i j}\right)_{5 \times 5}=\left[\begin{array}{ccccc}
0.5 & 0.25 & 0.2 & 0.2 & 0.33 \\
0.2 & 0.33 & 0.33 & 0.25 & 0.5 \\
0.5 & 0.25 & 0.25 & 0.33 & 0.2 \\
0.5 & 0.33 & 0.25 & 0.25 & 0.2 \\
0.5 & 0.2 & 0.33 & 0.25 & 0.2
\end{array}\right]
$$

Based on this matrix, the matching model proposed in this paper was used to solve the problem, and the target value and matching result of two-sided matching between cloud manufacturing tasks and cloud manufacturing resources at $t_{2}$ are obtained as follows:

$$
\begin{gathered}
Z\left(t_{2}\right)^{*}=1.1, \\
X_{13}=X_{21}=X_{32}=X_{45}=X_{54}=1 \text {, the rest of the } X_{i j}=0 .
\end{gathered}
$$

To sum up, the results of dynamic bilateral matching and static bilateral matching are compared, as shown in Table 13.

Table 13 Comparative analysis of dynamic two-sided matching results at different times

\begin{tabular}{|c|c|c|}
\hline State at different times & Target value & Matching result \\
\hline $\begin{array}{c}\text { Dynamic matching (considering } \\
\text { time } \mathrm{t}_{1} \text { and } \mathrm{t}_{2} \text { simultaneously) }\end{array}$ & $\mathrm{Z}=1.92$ & $\mathrm{u}=\left\{\left(\mathrm{X}_{1}, \mathrm{Y}_{4}\right),\left(\mathrm{X}_{2}, \mathrm{Y}_{1}\right),\left(\mathrm{X}_{3}, \mathrm{Y}_{3}\right),\left(\mathrm{X}_{4}, \mathrm{Y}_{5}\right),\left(\mathrm{X}_{5}, \mathrm{Y}_{2}\right)\right\}$ \\
\hline The matching at time $\mathrm{t}_{1}$ & $\mathrm{Z}=1.05$ & $\mathrm{u}\left(\mathrm{t}_{1}\right)=\left\{\left(\mathrm{X}_{1}, \mathrm{Y}_{3}\right),\left(\mathrm{X}_{2}, \mathrm{Y}_{2}\right),\left(\mathrm{X}_{3}, \mathrm{Y}_{4}\right),\left(\mathrm{X}_{4}, \mathrm{Y}_{1}\right),\left(\mathrm{X}_{5}\right.\right.$, \\
$\left.\left.\mathrm{Y}_{5}\right)\right\}$
\end{tabular}

From the analysis of Table 13, it can be seen that the target value of the matching scheme under multiple time series preference information is larger than the target value of the matching scheme at a single time $\left(\mathrm{t}_{1}\right.$, $\mathrm{t}_{2}$ ), which indicates that over time, the matching decision makers have a better understanding of the matching 
subjects. The information of matching preferences between cloud manufacturing tasks and cloud manufacturing resources increases continuously. Therefore, in order to give a reasonable target value and matching results for cloud manufacturing tasks and cloud manufacturing resources, it is necessary to consider the matching preference information at different times simultaneously.

\section{2 A comparative analysis}

In order to further clarify the research characteristics of this article, by comparing the current research methods with other documents the following conclusions can be drawn.

On preference information. Compared with the literature Zhang et al. (2019) and Yue et al. (2015), these paper consider the uncertainty of the preference information for two-sided matching subjects, and expand the preference information in a single form to multiple forms. Providing a way to solve the problem for two-sided matching problem with multiple forms of preference information. On the other hand, in the actual matching process, due to the differences of research background, knowledge and experience, decision-makers can assign different weights to each expert, it can ensure the objectivity and accuracy of the evaluation.

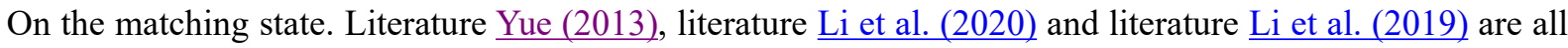
based on a static moment to study the bilateral matching of preference information. However, in the actual bilateral matching decision, the matching subject has different information at different moments. In this paper, the matching preference information at different moments is considered comprehensively, and the dynamic two-sided matching problem is studied, which is helpful to the matching results more scientific and closer to the actual situation.

On the matching model. Most of the existing two-sided matching models are based on the satisfaction perspective of matching and ignore the fairness and stability of matching. On the premise of seeking to maximize the matching satisfaction of two-sided subjects and minimize the matching fairness of two-sided subjects, this paper introduces the matching stability constraint to ensure that a stable matching relationship between two-sided subjects can be maintained.

On the model solution. In this paper, the objective weight coefficient is determined by matching competition degree, and the multi-objective optimization model is transformed into a single-objective programming model. Through this model, the matching results are feasible and accurate.

\section{Conclusions}

In this paper, a multi-expert group decision matching method for dynamic two-sided matching problems under the multi-form preference information is proposed. This method provides a new way to solve cloud manufacturing matching in uncertain environment.

Some highlights of this paper are concluded as follows:

1) In an uncertain environment, decision makers will give different forms of preference information based on their own experience. When decision-makers are uncertain about some judgments or unwilling to express their opinions, it will lead to the lack of preference information. Therefore, this paper considers three types of two-sided matching preference information with uncertainty, and constructs an ordinal vector matrix according to the characteristics of the uncertain preference information. By studying two-sided matching decision-making considering various forms of preference information, the theory of bilateral matching under uncertain environments can be enriched. By studying two-sided matching decision-making considering various forms of preference information, the theory of two-sided matching under uncertain environments can 
be enriched.

2) Due to differences in the knowledge system, judgment level and individual preferences of experts, the preference information given by experts may be subjective. In this paper, when integrating the preference information given by experts, each expert is given a different weight to ensure the objectivity and accuracy of group decision-making.

3) In a realistic matching problem, the decision information will change over time, the more information the matching subject has, the more influence it has on the matching decision. However, the traditional two-sided matching decision problem is almost limited to the static matching problem, it is necessary to consider the influence of preference information at different moments on the matching decision. The dynamic study of two-sided matching makes the matching result more scientific to reality.

4) In the matching process, stability constraints are introduced. Most of the existing two-sided matching methods under preference information are based on satisfaction and fairness, ignoring the stability of matching. This may cause some matching subjects to abandon the existing matching objects, thus making the original matching scheme invalid. Therefore, this article comprehensively considers the satisfaction, fairness and stability of matching, which is of great significance for achieving more scientific and effective cloud manufacturing matching.

The two-sided matching problem between cloud manufacturing tasks and cloud manufacturing resources is solved through the model proposed in this paper, and it also makes a sustainable contribution to achieving more scientific and effective cloud manufacturing matching.

It should be emphasized that this model not only makes up for the deficiency of existing research methods, but also can provide more choices for decision-makers to solve the dynamic two-sided matching problem with multiple types of uncertain preference information. However, in the cloud manufacturing two-sided matching problem, when a cloud manufacturing task requires more than one cloud manufacturing resource, there will be a one-to-many bilateral matching problem. Therefore, based on the research in this paper, future research will focus on building the one-to-many matching model of cloud manufacturing, and propose an efficient matching algorithm.

Acknowledgements Authors are thankful for generous help offered by professor Yu Yang.

Funding This research was supported by National Natural Science Foundation of China (Grant No. 71571023). And this study was also supported by the Fundamental Research Funds for the Central Universities (No.2020CDCGJX029). The authors are sincerely very appreciative that the anonymous can provide helpful comments to improve the quality of this paper.

\section{Declarations}

Conflict of interest The authors declare that they have no conflict of interest.

Ethical approval This article does not contain any studies with human participants or animals performed by any of the authors.

\section{Reference}

Chandrashekhar, H., \& Bhasker, B. (2011). Quickly locating efficient, equitable deals in automated negotiations under two-sided information uncertainty. Decision Support Systems, 52(1), 157-168. 
Chen, S. Q., Wang, Y. M., \& Shi, H. L. (2014). A dynamic matching decision-making method based on ordinal deviation fusion degrees. Operations Research and Management Science, 23(1), 59-65.

Chakraborty, A., Citanna, A., \& Ostrovsky, M. (2015). Group stability in matching with interdependent values. Review of Economic Design, 19(1), 3-24.

Fan, Z. P., Feng, B., \& Liu, Y. (2010). An approach to group decision-making with uncertain preference ordinals. Computers \& Industrial Engineering, 58(1), 51-57.

Fan, Z. P., Li, M. Y., \& Zhang, X. (2018). Satisfied two-sided matching: a method considering elation and disappointment of agents. Soft Computing A Fusion of Foundations Methodologies \& Applications, 22, $7227-7241$.

Gale, D., \& Shapley, L. (1962). College admissions and the stability of marriage. American Mathematical Monthly, 69(1), 9-15.

Jiang, Y. P., Kong, D. C., \& Yuan, D. N. (2017). Two-sided stable matching decision-making method with ordinal interval preference. Systems Engineering-Theory \& Practice, 37(008), 2152-2161.

Jiang, M. L., Lin, X. W., You, C., \& Ren, H. P. (2016). A method for group decision-making with uncertain preference ordinals based on probability matrix. Chemical Engineering Transactions, 51, 625-630.

Jia, H. L., Zhang, J., Qi, Y. M., \& Deng, S. P. (2020). Research on efficient matching strategy of cloud manufacturing platform resources and requirements. Modern Manufacturing Engineering, 475(04), 42-49.

Kushnir, A. (2013). Harmful signaling in matching markets. Games and Economic Behavior, 80, 209-218.

Kuhn, H. W. (1955). The Hungarian method for the assignment problem. Naval Research Logistic Quarterly, 2, 83-97.

Li, B. H., Zhang, L.Wang, S. L., Tao, F., Cao, J. W., Jiang, X. D., Song, X., \& Chai, X. D. (2010). Cloud manufacturing: a new service-orient ed networked manufacturing model. Computer Integrated Manufacturing Systems, (01), 1-7.

Li, Y. X., Liu, J. H., Zhang, H., Hou, Y. Z., He, Z. J., \& Fan, J. X. (2020). Bilateral matching methods for design tasks and knowledge resources in cloud manufacturing mode. Computer Integrated Manufacturing Systems, 1-14[2020-11-22].

Li, B. D., Yang, Y., Su, J. F., Liang, Z. C., \& Wang, S. (2020). Two-sided matching decision-making model with hesitant fuzzy preference information for configuring cloud manufacturing tasks and resources. Journal of Intelligent Manufacturing, 2020(1).

Li, B. D., Yang, Y., Su, J. F., Liang, Z. C., \& Wang, S. (2020). Two-sided matching decision-making model with hesitant fuzzy preference information for configuring cloud manufacturing tasks and resources. Journal of Intelligent Manufacturing, 2020(1).

Liu, W. F., \& Zhou, Y. W. (2013). A Group Decision-Making Model Based on Incomplete Complementary Judgment Matrices. Operations Research and Management Science, 22(1), 54-58.

Li, M. Y., Fan, Z. P., \& Liu, Y. (2012). A Method for two-sided Matching Based on Preference Ordinal Information. Operations Research and Management Science, 21(4), 112-118.

Li, B. D., Yang, Y., Su, J. F., Liang, Z. C., \& Wang, S. (2020). Two-sided matching decision-making model with hesitant fuzzy preference information for configuring cloud manufacturing tasks and resources. Journal of Intelligent Manufacturing, 2020(1).

Li, B. D., Yang, Y., Su, J. F., Zhang, N., \& Wang, S. (2019). Two-sided matching model for complex product manufacturing tasks based on dual hesitant fuzzy preference information. Knowledge-Based Systems, 186(Dec.15), 104989.1-104989.14.

Mao, J. J., Yao, D. B., Wang, C. C., \& Chen, H, Y. (2014). Group decision-making method based on time-series fuzzy soft sets. Systems Engineering - Theory \& Practice, 34(1), 182-189. 
Roth, A. E. (1985). The college admissions problem is not equivalent to the marriage problem. Journal of Economic Theory, 36(2), 277-288.

Sun, T., Zhang, D., Huang, G. H., Chen, Ye., \& Wan, L.Q. (2017). Method for Two-sided Matching with Multi-form Preference Information. Fuzzy Systems and Mathematics, 031(004), 108-116.

Wei, G. W., Huang, D. S., \& Wei, Y. (2007). Possibility degree method for uncertain linguistic multiple attribute group decision making. Sience paper on line, [2007-03-08].

Wei, G. W., Huang, D. S., \& Wei, Y. (2007). Possibility degree method for uncertain linguistic multiple attribute group decision making. Sience paper on line, [2007-03-08].

$\mathrm{Xu}, \mathrm{Z}$. S. (2004). Uncertain linguistic aggregation operators based on approach to multiple attribute group decision making under uncertain linguistic environment. Information ences, 168(1-4), 171-184.

You, T. H., Li, H. Y., \& Liu, C. N. (2013). A Method for Multiple Criteria Group Decision Making with Uncertain Preference Ordinals. Chinese Journal of Management Science, 21(005), 110-114.

Yue, Q. (2015). Decision method for two-sided matching based on order relations. Journal of Systems Engineering, 30(5), 601-606.

Yue, Q., Peng, Y. S., Yu, B. W., Hong, Y., \& Xiao, Q. (2015). Two-sided Matching Decision under Multi-granularity Uncertain Linguistic Environment. Next Generation Computer and Information Technology. $8(11), 35-44$.

Yue, Q., (2013). Decision method for the two-sided matching with uncertain preference ordinal information based on cumulative prospect theory. Journal of Systems Science and Mathematical Sciences, 33(9), 1061-1070.

Yue, Q., (2013). Decision Method for Two-sided Matching Based on Incomplete Score Information. Systems Engineering, 31(9), 79-83.

Yue, Q., (2014). Decision Method for Two-sided Matching Based on Score Information. Fuzzy Systems and Mathematics, 28(1), 106-112.

Yue, Q., \& Fan, Z. P. (2015). Decision method for two-sided matching based on incomplete ordinal number information. Journal of Management Sciences in China, 18(2), 23-35.

Yue, Q. (2015). Two-sided matching decision with two-granularity uncertain and incomplete linguistic terms. International Journal of Multimedia and Ubiquitous Engineering, 10(2), 121-128.

Zhao, J. H., \& Wang, X. H. (2016). Two-sided matching model of cloud service based on QoS in cloud manufacturing environment. Computer Integrated Manufacturing Systems, 22(001), 104-112.

Zhao, D. Z., \& Li, R. (2017). Two-sided matching mechanism with agents' expectation for cloud manufacturing resource. Control and Decision, 32(5), 871-878.

Zhang, J. (2020). Research on matching method of resource services in cloud manufacturing platform. (Doctoral dissertation).

Zhao, X. D., Zang, Y. Q., \& Luo, Y. Y. (2018). Method for dynamic two-sided matching decision making based on preference information. Computer Engineering and Applications, 54(5), 258-264.

Zhang, D., \& Zhu, B. Z. (2019). Satisfied, fair and stable two-sided matching method based on linguistic preference information. Systems Engineering -Theory \& Practice, 39(09), 236-244.

Zhao, X. D., Zang, Y. Q., \& Luo, Y. Y. (2018). Method for dynamic two-sided matching decision making based on preference information. Computer Engineering and Applications, 54(5), 258-264.

Zhang, D., Sun, T., Chen, Y., \& Wan, L. Q. (2019). Decision Making Method for Stable Two-sided Matching under Linguistic Preference Information. Operations Research and Management Science, 28(2), 60-66.

Zhang, D., Sun, T., Yan, C. D., Chen, Y., \& Wan, L. Q. (2018). Two-sided matching method considering 
psychological behavior of agents based on multi-form preference information. Computer Integrated Manufacturing Systems, 24(12), 220-227. 